From social burden to support elicitation: Development and validation of a new measure of workplace support elicitation experiences

Christopher M. Gallagher (ORCID:0000-0002-4986-2141)

Department of Psychology

Bowling Green State University

822 E Merry Ave, Bowling Green, OH 43403

Email: cmgalla@bgsu.edu

Ian M. Hughes* (ORCID:0000-0002-2923-2820)

Department of Psychology

Bowling Green State University

822 E Merry Ave, Bowling Green, OH 43403

Email: ihughes@bgsu.edu

Melissa G. Keith (ORCID:0000-0003-4722-4637)

Department of Psychology

Bowling Green State University

822 E Merry Ave, Bowling Green, OH 43403

Email:mgkeith@bgsu.edu

*Corresponding author.

Author Note.

We would like to thank Mike Zickar, Steve Jex, and Caitlin Porter for their helpful comments on earlier versions of the manuscript.

Manuscript accepted at Journal of Business and Psychology. 


\begin{abstract}
Receiving social support is widely considered a positive workplace phenomenon, but what about the employees from whom the support is being sought? Following recent calls from social support scholars, we focus on the "potential support provider" perspective of the social support dynamic and propose that the measure of social burden (Yang et al., 2016) currently used to capture this dynamic is significantly limited. In Study 1, we refine and expand the measure of social burden by constructing and validating a measure of support elicitation experiences (SEE) that distinguishes between emotionally laden SEE (SEE-E; explicit or implicit requests for support with an emotional valence) and instrumental SEE (SEE-I; explicit requests for work-related support). In Study 2, based on Conservation of Resources Theory, we examine how SEE-E and SEE-I differentially relate to work outcomes and explore the potential costs of providing support in response to these behaviors. Results demonstrate that our measure of SEE is an improvement over the social burden measure and support the empirical distinctiveness of emotionally laden (associated with negative outcomes) and instrumental (associated with positive outcomes) support elicitations. In addition, we find some evidence that routinely providing support for both SEE-E and SEE-I carries implications for undesirable workplace behavior. Findings from this research support the notion that there are often differential effects for the kinds of support we elicit from our colleagues and provides researchers with an improved instrument to assess the social support dynamic from the perspective of potential support providers.
\end{abstract}

Keywords: Social support, workplace behavior, job attitudes, social burden 


\section{From social burden to support elicitation: Development and validation of a new measure of workplace support elicitation experiences}

Social relationships are an important aspect of work and often manifest in a positive manner. Indeed, previous research has demonstrated that positive social relationships at work can improve employees' attitudes, performance, and overall well-being (e.g., Kahn, 1990; Schaufeli \& Bakker, 2004). Moreover, these relationships tend to have cross-level effects. For example, Bandiera et al. (2009) found that increased social connectedness of managers positively affected productivity at the level of the individual and upward to the entire firm. It would seem intuitive that having meaningful social relationships at work brings people closer together in ways that are beneficial for both the organization and the individual worker.

Social support, defined as "verbal and nonverbal communication between receiver and provider that reduces uncertainty about a situation, one's self, another, or a relationship" (Sias, 2009, p. 70), is an important aspect of social relationships in the workplace. Social support research has predominantly focused on the perceived availability or the reception of social support (Jolly et al., 2020). Recent research, however, has pointed to the importance of considering the potential costs of social support exchanges, namely the impact of being sought for support or providing support. In particular, Yang and colleagues (2016) suggested that support-seeking behaviors in the workplace, described by the authors as social burden (i.e., "behaviors from colleagues that elicit the focal employees' social support," p. 70), may lead to negative outcomes (e.g., burnout) for those who are being sought for support. Importantly, social burden and support provision are conceptually distinct. Although experiencing an implicit or explicit appeal for support may result in providing support, it does not have to, and individuals may experience negative outcomes even if they do not provide support. An example of social 
burden is instructive. After presenting to a group of coworkers, a colleague erupts in tears but does not direct their crying toward anyone in particular. Social norms suggest that someone comfort the coworker (Stryker \& Statham, 1985), making this an incidence of social burden. Regardless of whether one follows or contravenes (e.g., ignores the colleague) such norms, social burden has resulted.

The current research seeks to expand upon growing workplace social support research focused on the perspective of the potential support provider. To do so, we build on and refine the work of Yang et al. (2016), though we question the use of the term "social burden." Specifically, we suggest that this term connotes only negativity, although the valence and impact of requests for support may vary. Thus, in our first study, we develop a measure of support elicitation experiences (SEE), which refines Yang et al.'s social burden measure to include a wider range of behaviors by coworkers or supervisors that are likely to result in supportive actions.

Additionally, Yang et al. allude to the possibility for separable emotional and instrumental (i.e., work-related) dimensions, describing their measure as comprising two different types of experiences: salient displays of affect that are not aimed directly at targets but may be perceived as necessary to address, and implied or explicit requests for instrumental support. Although distinct empirical factors did not emerge in Yang et al.'s work (i.e., social burden is unidimensional), our first study finds that two factors of SEE emerge along largely expected lines: SEE that are emotionally laden (i.e., explicit or implicit requests for support with an emotional valence; SEE-E) and those that are instrumental (i.e., explicit requests for workrelated support; SEE-I). In a second study, we examine the possibility that the type of support elicited (SEE-E vs. SEE-I) has a differential impact on potential support providers' workplace 
attitudes and behaviors such as job satisfaction, counterproductive work behaviors, work engagement, organizational citizenship behavior, and microbreaks.

Taken together, we use two studies to develop and validate a measure of emotional and instrumental SEE — a refinement of the original social burden measure - and examine how these two types of elicitation relate to important work outcomes. In doing so, we contribute to the social support literature in several ways. First, we offer researchers a more balanced, content valid, and psychometrically sound scale to measure social support elicitations (née social burden) from the perspective of those being elicited (i.e., potential support providers). Next, we demonstrate that there are contrasting effects for the types of support we elicit from colleagues. Using a conservation of resources (COR; Hobfoll, 1989) theory lens, we hypothesize and find support for SEE-E being predictive of more undesirable outcomes and SEE-I being predictive of more positive outcomes. Finally, via path analysis, we find initial evidence that SEE-even kinds that result in positive outcomes - has the potential to be burdensome provided frequent support provision.

\section{Social Support}

To better understand the support elicitation construct space that the measure of social burden attempted to capture, we first situate these experiences within the larger context of social support. A majority of research on social support and its effects on health and stress-related outcomes developed from early research from Community and Clinical psychology (e.g., Caplan, 1974; Caplan et al., 1976). This research proposed that social support from family, friends, and coworkers is a robust and naturally occurring process and that such support is associated with reduced stress (Caplan, 1974). 
A breadth of continued research has provided support for this claim. Meta-analyses of social support and stress dynamics have uncovered that receiving social support negatively relates to workplace stressors including role stress, burnout, job dissatisfaction, and work-family conflict (Viswesvaran et al., 1999). Comparing sources of social support, French et al. (2018) concluded that combined workplace social support (i.e., organization, coworker, and supervisor) were far greater predictors of reduced work-family-conflict than nonwork sources.

For such an important dynamic, there remain gaps in our perspectives and knowledge of social support at work. In line with the Caplan (1974) conceptualization, the social support process is one that requires involvement from multiple parties, each with their own role and perspective. The majority of the social support literature, however, focuses primarily on two perspectives: the perceived availability of social support (judgments made prior to elicitation) and the reception of social support (e.g., Caplan et al., 1975; French et al., 2018). This focus has left the social support literature with a "perspective problem." Not much is understood about the other actors in the exchanges (e.g., those being asked for support, those providing support). Indeed, a recent review of social support research from Jolly et al. (2020) concludes by highlighting the need to explore alternative perspectives of the workplace social support process.

\section{Alternative Social Support Perspectives}

To highlight the variety of perspectives one may take when researching social support, we illustrate how a typical social support exchange is likely to unfold. In most circumstances, social support exchanges would begin with a requester (or an elicitor) who appraises the availability of social support before making it known - either directly (e.g., asking for help) or indirectly (e.g., salient affective displays) — that they require support. This elicitation for social support is received by colleagues, who are then placed in a position to provide support. This 
point in the social support process, from the perspective of those being sought (i.e., the potential support provider), is where Yang and colleagues' (2016) measure of social burden is focused. These elicited colleagues, if they so choose, would then provide support in response to the elicitation. When colleagues provide support to the support requester, the latter employee becomes the support recipient and is likely to enjoy positive outcomes (e.g., Viswesvaran et al., 1999). Research on the availability and reception of social support are dominant in the social support literature, whereas potential and actual support perspectives require further research (Jolly et al., 2020). Moving forward, we will focus on the potential support provider perspective, briefly surveying interdisciplinary research on support elicitations before detailing the research on social burden and what is known about the potential costs and demands associated with experiencing elicitations for social support at work.

Support Elicitations. Support elicitation behaviors have received ample attention from psychological scholars, specifically in the form of engaged help-seeking behavior. For example, clinical and social psychologists have long studied help-seeking in tandem with mental health; help-seeking behaviors often play an important role in facilitating resources to those struggling with mental disorders or other afflictions (e.g., Fischer \& Cohen, 1972; Hunt \& Eisenberg, 2010; Saunders et al., 1994). Help-seeking behavior in organizations has also received attention, particularly in the context of information-seeking strategies among newcomers (e.g., Miller \& Jablin, 1991; Morrison, 2002). More specifically, organizational newcomers tend to use helpseeking behaviors as a means of reducing uncertainty about their job, obtaining information about tasks or colleagues, and adjusting to the organization (Morrison, 2002). Although this research is important, it does not clarify the impact help-seeking behaviors may have on those experiencing the elicitations for support. 
Organizational research has only recently begun to explore the impact of support elicitations and how these elicitations affect potential support providers. Yang and colleagues (2016) published a study detailing social burden, a social-exchange construct defined as "behaviors from colleagues that elicit the focal employees' social support" (p.70). Importantly, social burden is measured from the perspective of the recipient of the elicitations (i.e., those being sought for support). Unlike related constructs wherein the social exchanges are solely negative (e.g., workplace incivility), social burden can be negative, neutral, or positive-contrary to the name's connotations. Upon repeated exposure, the authors posited that social burden may contribute to resource drain and stress. Empirical results provided support for this notion, as those who reported being exposed to greater amounts of social burden had increased burnout and physical symptoms, lower job satisfaction, and engaged in more counterproductive work behavior (CWB; intentional employee behavior that is harmful to the legitimate interests of an organization; Marcus et al., 2016). A recent study from Gallagher \& Hughes (2020) replicated these relations and, perhaps more interestingly, found in a post-hoc analysis that the two social burden items focused on salient affective displays demonstrated stronger relations with CWB than the two social burden items focused on implied or explicit requests for work-related support. This provides initial support for the idea that the modality and nature of the elicitation is of importance. Taken together, these findings provide a foundation for future research on workplace support elicitations.

\section{Refining Social Burden}

Although, research on social burden reflects an important step in advancing research on the elicitation of social support in organizational contexts, we suggest that its current conceptualization and measurement has limitations that could distort the construct's relations 
with predictors or outcomes. Below, we detail these perceived limitations and note how these limitations will be addressed by refining support elicitation measurement.

As noted, the conceptual definition of social burden was not restricted to strictly negative support elicitations. Rather, it is in line with a construct that is theoretically composed of an assortment of support-eliciting behaviors, varying in their valence and impact. The measure developed to capture the construct was, however, developed primarily from an item pool of negative social exchanges. This suggests that the support elicitation construct space was inadequately sampled, as there are a wide variety of eliciting experiences (i.e., positive, negative, and neutral). In the current research, we recommend support elicitation experiences (SEE) — a neutral moniker - as a label for this construct and attempt to capture support elicitations beyond those that are of negative valence in our item development process.

In addition, the authors provide limited information regarding item- or scale-level content validity. This is concerning, as establishing evidence for the validity of a measure's content is one of the fundamental components of scale development (American Educational Research Association, 2011). Providing item-level content validity evidence during the item generation process would help to ensure that the items correspond to the intended support elicitation construct space. Moreover, providing scale-level content validity evidence for the measure would instill confidence in the notion that the experiences captured are conceptually distinct from other, related workplace phenomena (Colquitt et al., 2019).

Finally, Yang et al. (2016) present social burden as a unidimensional construct. Although the authors supported this model via factor analysis, it seems to conflict with their description of the measure as being composed of two kinds of items (i.e., affective displays and requests for instrumental support). We propose that a more appropriate exploration of the dimensionality of 
this construct would be to include a wider range of item content. A multidimensional measure of support elicitation experiences may paint a more complex picture of this construct space.

Yang and colleagues' (2016) measure of social burden is an attempt to capture an important, yet understudied, perspective of the social support process. Clearly, though, refinement and expansion of the social burden measure is warranted if the potential support provider perspective of the social support dynamic is to be more fully examined. Across two studies, we refine and expand the measure of social burden to better assess the support elicitation construct space. Study 1 focuses on measurement development; here, we eschew the label of social burden and generate a wider range of items for potential inclusion. We also examine the factor structure of our new measure, provide item- and scale-level content validity evidence, and demonstrate incremental validity over the original social burden measure for predicting CWBan established outcome of social burden (e.g., Gallagher \& Hughes, 2020; Yang et al., 2016). In Study 2, we explore the relations between the reception of different types of support elicitation and job-relevant outcomes as well as investigate the role that providing support may play in affecting these relations.

\section{Study 1 Method}

\section{Item Pool Development}

Clark and Watson (1995) note that careful definition of the proposed construct is important for all later stages of scale development to proceed smoothly. Refining the definition used by Yang et al. ("behaviors from colleagues that elicit the focal employees' social support", 2016, p. 70), we opted for the definition: "behaviors by coworkers or supervisors which have as a likely response the provision of support" to clarify that the items do not indicate a provision of support. Next, rather than rely on negative social exchanges as a foundation for items, we 
referenced social support taxonomies (e.g., Barrera, 1986; Dignam \& West, 1988) across research disciplines. Specifically, a small team of I-O psychologists generated items based on dimensions of social support such that an item was generated that might elicit a type of social support. For example, the item "Complained of boredom in my presence or toward me" was written as a behavior that might elicit Nondirective Support (Barrera et al., 1981) such as chatting with the coworker to provide relief to the boredom. As such, the items represent a diversity of work-related and non-work related, emotional and instrumental support requests. Roughly 20 items were written, but this was reduced to 17 by removing highly redundant items.

Once the item-drafting phase was complete, fourteen subject matter experts (SMEs), including two faculty organizational health psychologists and twelve I-O graduate students ranging from years two to five, were recruited to rate the extent to which the items represented the construct (see Table 1). Table 1 includes the Hinkin and Tracey (1999) index for construct correspondence (i.e., $h t c$ ) for each item. This index ranges from 1 when all raters select the greatest correspondence anchor for an item, to 0 when all select the lowest correspondence anchor for an item. We eliminated items below $h t c=.70$, determining these items suspect in definitional correspondence. Although not initially guided by the study, .70 represents the bottom percentile of $h t c$ among a large sample of established organizational scales in a broad exploration of content validity (Colquitt et al., 2019), suggesting our heuristic is in line with the published literature. Owing to their initial work on the construct and serving as a point of comparison, we retained the social burden items of Yang et al. (2016) regardless of SME ratings. In total, 11 items (inclusive of 7 newly developed items and the 4 social burden items) were retained for data collection and measure development (see Table 1).

\section{Participants and Procedure}


Five hundred and twenty-five U.S. participants were recruited via Amazon's Mechanical Turk (MTurk) and allowed to participate if their income did not rely primarily upon MTurk and they worked at least 20 hours per week excluding MTurk. Of the initial sample, 34 failed to meet the inclusion criteria, pass attention checks (correct responses for at least two of three attention check items; Thomas \& Clifford, 2017), or were responding outside the United States. The remaining sample $(N=491)$ had an average age of $37(S D=11)$ and were predominantly female $(60 \%)$ and white $(81 \%)$.

As suggested by best practices in scale development (e.g., Clark \& Watson, 2019), only a portion of these participants were used to create our measure of SEE. Data were randomly split in two: an initial scale development sample $(n=299)$ used for exploratory factor analysis (EFA), and a hold-out sample $(n=192)$ used to both examine relations to support criterion-related validity and verify our proposed structure of SEE using confirmatory factor analysis (CFA). Using a hold-out sample increases the confidence that results of subsequent analyses are not attributed to characteristics of the exploratory sample that may have led to the covariance pattern leading to the items selected for the final measure (e.g., Freedson et al., 2012). We follow the traditional psychological validation process consisting of EFA followed by CFA.

\section{Scale Creation}

Yang et al. (2016) presented social burden as a unitary construct, however, as previously mentioned, inspecting the measure warranted further empirical examination. Accordingly, the 11 items, treated as continuous indicators, (whose responses were rated on a 1 to 5 scale: $1=$ Never, $2=$ One to three times a month, $3=$ Once or twice per week, $4=$ Several times per week to once per day, $5=$ Multiple times per day) were subjected to an EFA using maximum likelihood estimation and geomin rotation to extract and interpret factors (see Table 2; Muthén \& Muthén, 
2015). Parallel analysis (Figure 1) suggested two factors, and the oblique geomin rotation yielded two meaningful dimensions with a factor intercorrelation of .54: one dimension regarding emotional behaviors or situations and one dimension regarding explicit, mostly workrelated, requests for help. Research determining the exact factor loading thresholds for item retention can be mixed, and many thresholds have been proposed, such as .7 (Hair et al., 2010) or .4 or .5 (Hulland, 1999; Tabachnick et al., 2007). We began by eliminating items with loadings below .5 on their primary factor (Clark \& Watson, 2019; Tabachnick et al., 2007). The instrumental or work-related dimension contained only three items above this threshold, and with the intentions of balancing scale length, we removed the two worst remaining indicators from the emotion-related scale. The resulting measure contained two SEE scales: emotionally laden SEE (items 1, 4, and 5; SEE-E) and work-related or instrumental SEE (items 7, 8, and 11; SEE-I) ${ }^{1}$. Once the factor structure of the SEE construct was revealed via EFA, we subjected each subscale to reliability analyses. We use McDonald's (1999) omega to denote the reliable variance in our SEE measure. Both the SEE-E $(\omega=.79)$ and SEE-I $(\omega=.83)$ subscales demonstrated satisfactory reliability in the scale development sample $(n=299)$.

It is important to verify the proposed structure of our construct in a separate sample using more confirmatory methods. To do this, CFA were conducted using data from the hold-out sample $(n=192)$. First, we tested how well our proposed two-factor structure of SEE fit the data. Per recommendations from Kline (2015), a model fit statistic (i.e. $\left.\chi^{2}\right)$ and three fit indices were used to assess model-data fit: the root mean square error of approximation (RMSEA; Steiger, 1990), Bentler's Comparative Fit Index (CFI; Bentler, 1990), and the standardized root mean square residual (SRMR). In each case, the two-factor model, which yielded a factor

\footnotetext{
${ }^{1}$ It should be noted that the SEE-E scale carried over two items from the social burden scale focused on salient affective displays (Items 1 and 4 in Table 1).
} 
intercorrelation of .32, demonstrated satisfactory fit: RMSEA $=.013,95 \%$ CI $[.00, .086]$

(RMSEA results indicate "excellent" fit per MacCallum and colleagues (1996)), CFI = .999, and $\mathrm{SRMR}=.038$. In addition, our $\chi^{2}$ test denoted satisfactory fit, $\chi^{2}(8)=8.27, p=.41$. We then compared our two-factor model to the unidimensional model; the two-factor model had significantly better fit than the unidimensional model, $\chi^{2}(1)=158.52, p<.01$. These results help to provide structural evidence of validity for the measure and taxonomy of SEE.

Given the growing problem of construct proliferation in the organizational sciences (Shaffer et al., 2016) and the lack of content validity evidence presented by Yang et al. (2016), we conducted a scale-level content validation of our SEE measure using Colquitt et al. (2019) as reference. To do so, we recruited 39 subject matter experts (i.e., industrial-organizational psychology faculty and graduate students) and had them complete an item-sorting task popularized by Anderson and Gerbing (1991). In the task, participants were asked to match a set of items, comprising 4 different constructs, to definitions of the 4 constructs included in the item set. The four included constructs were: SEE, content of supervisor communications (Beehr et al., 1990), workplace incivility (Matthews \& Ritter, 2016), and OCB-altruism (Podsakoff et al., 1990). Two indices were used determine scale-level content validity: the proportion of standard agreement $\left(p_{s a}\right)$ and the substantive validity coefficient $\left(c_{s v}\right)$. Both of the SEE scales exhibited satisfactory (i.e., moderate to strong) content validity, judging by Colquitt and colleague's (2019) benchmarks: SEE-E: $p_{s a}=.77, c_{s v}=.56$; SEE-I: $p_{s a}=.88, c_{s v}=.80$. See Appendix A for more information on this process.

We turn now to initial evidence of convergent and discriminant validity for our measure of SEE, divided into SEE-E and SEE-I. Here, we focus on CWB as an outcome of SEE. CWB is a family of harmful behaviors that have consistently shared positive relations with social burden 
in past research (Gallagher \& Hughes, 2020; Yang et al., 2016) —relations thought to be due to social burden behaviors' potency as a social stressor.

\section{Measures}

Social Burden. Social burden was measured using Yang et al.’s (2016) four-item scale. The omega coefficient for this scale was .76 in the holdout sample. The instructions administered for social burden and the SEE measure were: "Our colleagues (co-workers or supervisors) engage in many behaviors in the workplace. Please indicate how often your colleagues have engaged in each behavior in the previous 30 days." Responses were rated on a 1 (Never) to 5 (Several times per day) scale.

Support Elicitation Experiences. The previously described 6-item measure of SEE was used to assess support elicitation experiences at work. This measure captures emotionally laden support elicitation experiences (SEE-E) and instrumental support elicitation experiences (SEE-I). The omega coefficients for these subscales were .79 and .81 , respectively, in the holdout sample. Responses were rated on a 1 (Never) to 5 (Several times per day) scale.

CWB. CWB was operationalized using Spector et al.'s (2006) 32-item measure of CWB, which can be broken down into five subscales: abuse, withdrawal, production deviance, theft, and sabotage. The omega coefficients for these subscales in the holdout sample were $.96, .89$, $.86, .86$, and .76 , respectively. Responses were rated on a 1 (Never) to 5 (Every day) scale.

\section{Study 1 Results}

Descriptive statistics and correlations can be found in Table 3. Within the hold-out sample $(n=192)$, SEE-E related uniformly to all CWB scales: abuse $(r=.48,95 \%$ CI $[.36, .58]$, $p \leq .01)$, production deviance $(r=.46,95 \%$ CI $[.34, .56], p \leq .01)$, withdrawal $(r=.43,95 \%$ CI $[.31, .54], p \leq .01)$, sabotage $(r=.43,95 \%$ CI $[.31, .54], p \leq .01)$, and theft $(r=.42,95 \%$ CI $[.30$, 
$.53], p \leq .01)$. SEE-I, meanwhile, was significantly related only to production deviance $(r=.16$, $95 \%$ CI $[.02, .30], p \leq .05)$ and withdrawal $(r=.25,95 \%$ CI $[.11, .38], p \leq .01)$.

The current research refines and introduces dimensional nuance to an extant measure (i.e., social burden; Yang et al., 2016). We believe it is important to demonstrate that, although the original 4-item measure predicted CWB (Gallagher \& Hughes, 2020; Yang et al., 2016), the new measure explains incremental variance over this measure in the prediction of outcomes. To do this, we tested social burden, SEE-E, and SEE-I in the prediction of the types of CWB using multiple regression. In each case, social burden was included in the first step of the analyses.

Results indicated that SEE, specifically SEE-E, predicted above and beyond social burden in the prediction of abuse $\left(\Delta R^{2}=.04, F(3,188)=18.68, \beta=.38, t(188)=3.21, p \leq .01\right)$, production deviance $\left(\Delta R^{2}=.04, F(3,188)=16.93, \beta=.36, t(188)=3.03, p \leq .01\right)$, withdrawal $\left(\Delta R^{2}=.05\right.$, $F(3,188)=16.40, \beta=.37, t(188)=3.09, p \leq .01)$, sabotage $\left(\Delta R^{2}=.05, F(3,188)=14.67, \beta=\right.$ $.39, t(188)=3.23, p \leq .01)$, and theft $\left(\Delta R^{2}=.06, F(3,188)=13.87, \beta=.43, t(188)=3.50, p \leq\right.$ .01). SEE-I did not share any significant relations with CWB beyond social burden in these analyses. See Table 4 for complete regression information regarding these analyses.

\section{Study 1 Discussion}

In her dissertation, Yang (2009) drew from an item pool of negative social interactions to create the initial social burden measure - a construct defined, in part, by those negative items. When further developing the social burden construct, however, Yang et al. (2016) updated the definition of this construct (while still primarily drawing from said item pool) to include potentially positive interactions. This definitional updating process should be commended, but measurement changes should follow. We move away from the social burden moniker to strip away the negative valence of a term like "burden" and instead referred to these behaviors as 
SEE, as this label better reflects the nuance of these interactions. Study 1 addresses the measurement aspect of construct updating by expanding the measure to include more diverse content in line with the construct's conceptual definition. This increased content coverage likely resulted in our two-dimensional model of SEE: SEE-I (explicit requests for work-related support) and SEE-E (explicit or implicit requests for support with an emotional valence).

SEE-E and social burden had relatively strong positive relationships with the different types of CWB, which is not surprising given the overlapping items. Whereas the correlation between the two was rather large $(r=.84)$, when estimated after removing the overlapping items, the correlation (i.e., between SEE-E and social burden) was reduced to .43. Despite this, our incremental validity analyses demonstrate that our SEE-E subscale more strongly predicts the harmful behaviors associated with social burden but with fewer total items.

SEE-I was found to be positively related to both production deviance and withdrawal behaviors, two kinds of organizationally targeted deviance. Our incremental validity analyses, however, revealed that SEE-I was not significantly related to any type of CWB when included in the same step as SEE-E. This suggests that the explained variation in CWB is driven by SEEE- the more inherently problematic or difficult set of workplace social exchanges. In Study 2, we suggest that SEE-E is likely more "burdensome" relative to SEE-I because SEE-E is more likely to be appraised as a threat to resources.

Previous studies under the social burden paradigm have suggested that asking colleagues for help, explicitly or implicitly, unequivocally leads to poor outcomes for the colleague being asked, but our Study 1 calls this into question. Specifically, features of support elicitationshere, emotional vs. instrumental requests_-lead to unique patterns and magnitudes of relations 
with CWB facets. As such, this study represents a step in providing evidence of the validity of the multidimensional model of SEE and offers a glimpse at potential future research in this area.

\section{Study 2}

Support elicitation experiences appeared to be divided into SEE-E (emotionally laden elicitation experiences) and SEE-I (instrumental elicitation experiences). Using our measure, Study 2 investigates how SEE-E and SEE-I relate to both positive and negative workplace outcomes (e.g., work engagement, CWB, job satisfaction). To guide our hypothesized relations, we draw from Conservation of Resources Theory (COR; Hobfoll, 1989) and its applications throughout the social support literature.

\section{COR Theory and SEE}

COR theory is a motivational framework that explains why people behave or feel the way they do when stressed, with the key assumption being that people strive to acquire, maintain, and protect their resources (Hobfoll, 1989, 2001). It is often used to explain the costs and benefits associated with social support processes (in that social support often creates resource reservoirs; Jolly et al., 2020), and helps explain the divergence in outcomes we anticipate between SEE-E and SEE-I.

According to COR theory, psychological stress occurs in three ways: when 1) resources are lost, 2) resources are not regained after they are invested, and 3) resources are threatened with loss. When elicited for support, potential support providers are likely to evaluate the form of the elicitation as well as the costs and benefits of the potential support response, and these evaluations factor into whether the elicitation is experienced as a potential threat to one's resources. Importantly, although experiencing SEE and providing support are distinct, prior research has indicated that those in positions to help others often evaluate the costs of helping 
behaviors before committing to or refraining from such behavior (e.g., Axelrod, 1984; Olson, 1989; Taylor, 2002).

We anticipate differences in the valence of outcomes between SEE-E and SEE-I because of how these elicitations are likely to be appraised by potential support providers. These differential appraisals likely stem from the form of these elicitations and evaluations of their potential support responses. SEE-E is more likely to be appraised as a threat to resources (i.e., the potential loss of means to achieve one's valued goal; Demerouti et al., 2001; Halbesleben et al., 2014) due to higher potential for disruptiveness, discomfort, and emotional labor, thus leading to negative outcomes (e.g., CWB). Conversely, SEE-I is less likely to be experienced as a threat to resources, given their instrumental nature, and may even be appraised as a positive event that grants resources due to the potential for positive affect and feelings of confidence and cooperation, thus leading to positive outcomes (e.g., work engagement).

In the following sections we further explicate why we expect SEE-E and SEE-I to result in differential outcomes drawing from COR theory and related research. Notably, the goal of this study is not to test the causal mechanisms proposed in the theory, but rather, to use this theory as a guiding framework to examine how SEE-E and SEE-I may differentially relate to relevant outcomes. Thus, the explanatory mechanisms described in the following sections are not explicitly tested.

\section{Emotionally Laden Support Elicitation Experiences}

SEE-E (i.e., implicit or explicit requests for support with an emotional valence) is likely to relate to many negative outcomes including negative emotions as a result of these elicitations being appraised as a threat to resources (Hobfoll, 2001; et al., 2003). This appraisal is likely to come from the implicit and disruptive forms these elicitations may take, as well as evaluations of 
their potential, appropriate support response (i.e., emotional support provision). This threat to resources, however, has to be balanced against the "good colleague" norm, in which employees are expected to be cooperative and helpful (Stryker \& Vryan, 2006). Thus, SEE-E represents a family of behaviors that can create discomfort and engender conflict between conserving resources and providing emotional support.

There are numerous reasons why SEE-E may be appraised as a threat to resources. To begin, SEE-E, in part, concerns implicit requests for support that take the form of salient emotional outbursts or displays (e.g., acted emotionally upset in one's presence but not towards them). These kinds of elicitations are likely to be particularly threatening for potential support providers' resources, as they are difficult to ignore, violate the mild-mannered display rules (i.e., rules for emotional expression which guide employee emotion-expression regulation; Ekman \& Friesen, 1975) inherent to most organizations (e.g., Kelly \& Barsade, 2001), and lack a clear target — contributing to feelings of ambiguity (e.g., "should I help, or will someone else?”), a known potential driver for stress (e.g., Budner, 1962).

Evaluations of the potential response for SEE-E (i.e., the provision of emotional support) are also likely to contribute to SEE-E being appraised as a threat to resources. First, this response may be identified as requiring some degree of emotional labor for the would-be supporter. If typical workplace norms would compel employees to provide support for SEE-E, it stands to reason that the proper display rules would dictate that those employees respond calmly and positively. For example, in a scenario where a coworker outwardly expresses anger over a poor performance review, the colleague witnessing this anger may experience pressure to express sympathy for the coworker while feeling that the evaluation was warranted. Enhancing, faking, or suppressing one's emotions, particularly on a moment-to-moment, surface-level basis, 
however, can result in negative workplace outcomes such as job dissatisfaction, burnout, and turnover intentions (Brotheridge \& Grandey, 2002; Chau et al., 2009; Hülsheger \& Schewe, 2011). In addition, potential support providers may judge the appropriate support response to SEE-E as being confusing or difficult. The appropriate behavioral response to witnessing particularly potent SEE-E, such as salient emotional displays (e.g., someone losing their temper near you), is often ambiguous (Lane \& Klenke, 2004). That is, it is not always clear how one should respond or react to SEE-E, causing personal distress. Altogether, employees are likely to appraise SEE-E as a significant threat to their cognitive and affective resources, as these elicitations can disrupt and cause discomfort, and their proper response would often be the provision of emotional support — a response that may require emotional labor, with all its potential unwanted results.

We propose that employees routinely exposed to SEE-E may react or cope in several different ways. Per COR theory, when people perceive their resources to be stretched or exhausted, they enter a defensive state often characterized by aggression as a means of preserving remaining resources (Hobfoll et al., 2018). In this vein, we anticipate SEE-E to result in abusive behavior towards others at work, as these hostile behaviors would likely prompt colleagues to avoid the potential support provider — protecting their remaining resources. Additionally, to cope with the stress generated from threats to resource loss, employees may engage in withdrawal and production deviance behaviors. These behaviors are particularly likely when the individual has little control over the stressor (Krischer et al., 2010), such as when a coworker makes unsolicited emotional requests for support. As a result, employees are likely to withdraw (e.g., arriving late to work) and withhold production (e.g., purposefully working slowly) to preserve cognitive and affective resources. Notably, withdrawal and production 
deviance represent a more harmful coping strategy (Marcus et al., 2016), whereas microbreaks (i.e., short, nonwork respite activities; Kim et al., 2017) may be a neutral or beneficial coping strategy. Workers experiencing resource loss from routine SEE-E may take microbreaks to replenish lost resources (Halbesleben et al., 2014; Westman \& Eden, 1997). Altogether, SEE-E may result in negative workplace outcomes or coping behaviors:

Hypotheses 1a-d: SEE-E is positively related to (a) abusive work behavior, (b) withdrawal, (c) production deviance, and (d) microbreaks.

\section{Instrumental Support Elicitation Experiences}

In contrast to SEE-E, SEE-I (i.e., explicit requests for work-related support) is less likely to be perceived of as a threat to employee cognitive and affective resources, and more likely to be perceived as a positive event that grants resources and catalyzes future resource gains. As with SEE-E, this difference in appraisal is due in large part to the form of these elicitations and evaluations of their appropriate, potential support response (i.e., instrumental support provision). We contend that these elicitations are likely to be positively appraised, and that experiencing such elicitations will lead to a variety of outcomes that have a positive valence. Akin to SEE-E, support does not have to be provided for the outcomes of SEE-I to arise.

Although SEE-E partly concerns implicit requests for support that take the form of salient emotional displays or outbursts (e.g., someone losing their temper near you but not towards you), SEE-I exclusively concerns explicit requests for instrumental support. This means that that these elicitations lack the target ambiguity, display rule violations, and disruptiveness inherent to implicit forms of SEE-E. As a result, potential support providers are less likely to perceive the potential for resource loss when confronted with SEE-I, in contrast to implicit SEE-E. In fact, potential support providers may find these explicit, work-related elicitations appealing. Prior 
research has indicated that being asked for work-related help on the job is often a positive event, generating state positive affect (Basch \& Fisher, 2000; Bledow et al., 2011).

Evaluations of the potential support response were the other theoretical driver for the detrimental outcomes of SEE-E, in that the potential support response would be judged as unattractive for potential support providers due to the potential for emotional labor, discomfort, and negative emotions - helping to render SEE-E a threat to resources. The potential support response of SEE-I, however, is likely to have a different evaluation. For example, the potential for emotional labor is reduced since these explicit work-related requests do not contain a salient affective component. It should be noted that while SEE-I may, in some situations (e.g., times where the potential support provider is under significant time pressure), also represent a conflict for potential support providers between conserving resources and being helpful akin to SEE-E, this conflict is less likely to be strenuous. Aside from the probable lack of emotional labor, it is also likely to be easier to refuse to provide support to SEE-I than it is for SEE-E. For example, if a potential support provider was under a significant amount of time pressure and a coworker approached and asked them to demonstrate how something worked (SEE-I), there is more room for the potential support provider to explain they are busy or request that they be able to provide support at a later time. Conversely, if someone approached that same employee to discuss something emotionally difficult (SEE-E), not feeling pressure to respond with kindness and provide immediate support would be much more difficult—making the conflict between conserving resources and being helpful much more salient and potent. Altogether, the potential support response to SEE-I is, in contrast to SEE-E, less likely to be judged as a threat to cognitive and affective resources. 
As a result of the appraisals of SEE-I, we anticipate that experiencing SEE-I is likely to bestow resources to focal employees as opposed to draining them. As mentioned previously, past research has demonstrated that being asked for work-related support may generate state positive affect (Basch \& Fisher, 2000; Bledow et al., 2011). Moreover, scholars have suggested that work-related exchanges help place focal employees in a network of cooperation and communication with their peers (Sonnentag, 2000). Thus, we contend that exposure to SEE-I is likely to grant cognitive and affective resources. More specifically, potential support providers may experience feelings of work-related confidence upon being asked for help, as they are likely to perceive their intellect and work-related judgment as being valued by others. Furthermore, potential support providers may begin to feel closer to their colleagues as SEE-I accumulates, as these requests are likely to establish feelings of trust and interdependence between them and their colleagues. In turn, potential support providers who experience SEE-I are, as a result of gained cognitive and affective resources, likely to possess higher levels of work engagement and job satisfaction. These gained resources can then be invested as a means of protecting future resources or creating resource reservoirs; such investment is the catalyst for resource gain spirals, wherein resources gained from one positive exchange (in this case, SEE-I) have the potential to engender future positive social exchanges that would further contribute valuable resources to participating parties (Hobfoll, 2001). We anticipate that employees who experience SEE-I will, in an effort to both create resource reservoirs in the form of colleague and organizational support and contribute to future resource gains, invest these gained resources into both the organization and its members in the form of organizational citizenship behavior (OCB; i.e., intentional behaviors that benefit the organization or its members; Organ, 1997). Altogether, we suggest that exposure to SEE-I will result in higher levels of work engagement, job satisfaction, and OCB. 
Hypotheses 2a-c: SEE-I is positively related to (a) work engagement, (b) job satisfaction, and (c) organizational citizenship behavior.

\section{The Costs of Providing Support}

Although we have argued that SEE-E is more detrimental than SEE-I, it is likely that routinely providing support to either kind of request carries implications for how employees behave on the job. In instances of repeated support, an employee may begin to experience cognitive or affective resource loss and become burdened or stressed. These employees will then look to protect their remaining resources, perhaps in aggressive or harmful ways as noted earlier (Hobfoll et al., 2018). If the detrimental outcomes related to SEE are largely explained by whether people are providing support to the elicitations, this would be suggestive of a different mechanism than if they are not. We will take an exploratory approach to this question and assess how the cumulative provision of support affects the relations both types of SEE share with behavioral strain at work (i.e., withdrawal, production deviance, abusive work behaviors).

Research Question: To what extent are the detrimental outcomes of SEE explained by the provision of support?

\section{Study 2 Method}

\section{Participants and Procedure}

We recruited 1,376 participants through MTurk and allowed them to participate if (1) their income did not rely upon MTurk and (2) they worked at least 20 hours per week excluding MTurk. Of the 1,376 participants, 642 were excluded from the analyses for either submitting an incomplete dataset (i.e., missing over $50 \%$ of the items), missing items on our focal construct (SEE), missing any attention check items, or responding from outside of the United States. The final sample $(N=734)$ was slightly more female $(51.6 \%)$ and primarily white $(81.5 \%)$. 


\section{Measures}

SEE. We used the 6-item measure developed in Study 1. Responses ranged from 1 (Not at all) to 5 (Multiple times per day). The omega coefficients for SEE-I and SEE-E were .75 and .79 , respectively.

OCB. To measure frequency of OCB, we used the 20-item OCB-C (Fox et al., 2012). Responses ranged from 1 (Never) to 5 (Every day). An example item was "Helped a co-worker who had too much to do." The omega coefficient for this scale was .96.

Abusive Work Behavior. To measure abusive behavior at work, we used 5 items from the 10-item Counterproductive Work Behavior Checklist (CWB-C)² (Spector et al., 2010). Five items were omitted from this scale as they do not represent abusive workplace behaviors. These five items are also present in the combined samples of the EFA and CFA in Study 1. Using the EFA sample from Study $1(N=491)$, we found that the correlation between the original 17-item abuse scale of the CWB-C (Spector et al., 2006) and the 5 items used here was $r=.96$, with a reduction in internal consistency from .95 to .84 . Thus, although some minor differences between the two measures exists, we have confidence that both forms measure the same construct. Responses ranged from 1 (Never) to 5 (Every day). An example item was "Insulted someone about their job performance." The omega coefficient for the scale in this collection was .89 .

Withdrawal. To measure withdrawal, the 4-item withdrawal subscale from the 32 -item CWB-C was used (Spector et al., 2006). Responses ranged from 1 (Never) to 5 (Every day). An example item was "Came to work late without permission." The omega coefficient for this scale was .81.

\footnotetext{
${ }^{2}$ These five items correspond with abuse items found on the 32-item CWB-C (Spector et al., 2006).
} 
Production Deviance. The 3-item production deviance subscale from the 32-item CWBC was used (Spector et al., 2006) was used. Responses ranged from 1 (Never) to 5 (Every day). An example item was "Purposely worked slowly when things needed to get done." The omega coefficient was .86 .

Job satisfaction. To measure job satisfaction, the 4-item Job Satisfaction Index from Quinn and Shepard (1974) was used. Responses ranged from 1 (Strongly disagree) to 5 (Strongly agree). An example item was "All in all, I am satisfied with my job." The omega coefficient for this scale was .91 .

Work engagement. To measure work engagement, the 9-item short form of the Utrecht Work Engagement Scale was employed (Schaufeli et al., 2002). Responses ranged from 1 (Never) to 7 (Always). An example item was “At my work, I am bursting with energy." The omega coefficient for this scale was .96 .

Microbreaks. To assess frequency of microbreaks, we used the 9-item Microbreaks scale from Kim and colleagues (2017). Responses ranged from 1 (Never) to 5 (Very frequently). An example item was "Chatting with coworkers on nonwork-related topics." The omega coefficient for this scale was 79 .

Inferred Provision of Support. To assess whether support was provided for our SEE items, we created a proxy index using items from the Organizational Citizenship Behavior Checklist (OCB-C; Fox et al., 2012), drawing from past research (e.g., Halbesleben \& Wheeler, 2015) that has utilized this measure in a similar manner (i.e., the investment of personal resources in the form of providing social support). To build this index, two authors rated all OCB-C items on a 1 to 5 scale regarding whether they could be seen as responses to SEE items. For example, the OCB-C item "Helped co-worker learn new skills or shared job knowledge" was 
rated highly, matching the SEE-I item "Asked me to explain how something works." Items that had an average rating of over 3 were included in our scale. Altogether, our Inferred Provision of Support index included 5 items, scaled 1 (Never) to 5 (Every day), with an omega coefficient of .85. The complete OCB-C ratings can be found in Table 5.

\section{Study 2 Results}

To provide further evidence of construct validity and test our specific hypotheses, we present zero-order and partial correlations with our criteria. Specifically, the partial correlations of each SEE dimension with the criteria were calculated controlling for the opposing dimension (e.g., SEE-I correlated with job satisfaction, controlling for SEE-E). As these two dimensions correlate at roughly .5 in both analyses in Study 1, the partial correlations paint a clearer picture of each dimension's relations in isolation.

Table 6 displays means, standard deviations, Pearson, and partial correlations. A full matrix of bivariate correlations can be found in Appendix B. Although the SEE dimensions share substantial variance, the zero-order correlations remain illustrative, adding evidence of discriminant and convergent validity. For example, SEE-I correlates positively and significantly with the number of hours worked by participants $(r=.16, p<.001)$, whereas SEE-E is not significantly correlated with hours. This would be expected if SEE-I leads to aiding others in their work before completing one's own. Although the pattern of bivariate correlations offers some validity evidence for the SEE dimensions, we turn to our hypotheses for a more nuanced view via partial correlations (denoted $\left.r_{1}\right)$.

Hypothesis 1 stated that SEE-E would be positively related to abusive behavior, production deviance, withdrawal, and microbreaks. In support of this hypothesis, SEE-E was significantly related to abusive behavior $\left(r_{1}=.33, p<.01\right)$, withdrawal $\left(r_{1}=.24, p<.01\right)$, 
production deviance $\left(r_{1}=.32, p<.01\right)$, and microbreaks $\left(r_{1}=.18, p<.01\right)$. Hypothesis 2 stated that SEE-I would be positively related to work engagement, job satisfaction, and OCB. Supporting this hypothesis, SEE-I was significantly related to work engagement $\left(r_{1}=.20, p<\right.$ $.01)$, job satisfaction $\left(r_{1}=.12, p<.01\right)$, and OCB $\left(r_{1}=.30, p<.01\right)$. This general pattern supports the notion that the isolated statistical effects of SEE-I are generally positive, as seen in positive relations with job satisfaction and work engagement, whereas SEE-E has the inverse relations. Similarly, SEE-E exhibits sizeable partial correlations with CWB dimensions, whereas SEE-I is either inversely or not significantly related. Thus, SEE-E may be seen as generally detrimental in the work context.

To test our Research Question focused on providing support to both types of SEE, we conducted a path analysis using the lavaan package in R (Rosseel, 2012). SEE-E, SEE-I, the inferred provision of support, withdrawal, production deviance, and abuse were included in our fully saturated (i.e., assuming perfect fit) path model (see Figure 2). Direct effects from SEE-E to withdrawal $(\beta=0.45,95 \% \mathrm{CI}[0.34,0.58])$, SEE-E to production deviance $(\beta=0.55,95 \% \mathrm{CI}$ $[0.43,0.67])$, and SEE-E to abusive work behavior $(\beta=0.55,95 \%$ CI $[0.41,0.68])$, as well as from SEE-I to production deviance $(\beta=-.16,95 \%$ CI $[-0.27,-0.06])$ were significant. Standardized indirect effects were calculated using bootstrapping, as recommended by Hayes (2013). Significant indirect effects from SEE-E to withdrawal ( $\beta=0.05,95 \%$ CI $[0.02,0.09])$, SEE-E to production deviance $(\beta=0.07,95 \%$ CI $[0.03,0.12])$, SEE-E to abusive work behavior $(\beta=.07,95 \%$ CI $[0.03,0.11])$, SEE-I to withdrawal $(\beta=0.10,95 \%$ CI $[0.05,0.15])$, SEE-I to production deviance $(\beta=0.07,95 \% \mathrm{CI}[0.04,0.12])$, and SEE-I to abusive work behavior $(\beta=$ $.11,95 \%$ CI $[0.06,0.17])$ were observed through provision of support using 10,000 biascorrected percentile bootstrapped samples. See Table 7 for a complete breakdown of direct and 
indirect effects. These findings are suggestive of a cumulative negative effect for SEE when providing support routinely, even when SEE-I is experienced simultaneously.

\section{Study 2 Discussion}

One of the key propositions from Study 1 was the notion that the elicitation of support is not invariably harmful, and that the type of support and the way it is elicited predicts different kinds and levels of outcomes. The partial correlation results from Study 2 offer support for this claim. The effects of SEE-E tend to relate to undesirable organizational outcomes (e.g., withdrawal, abuse). Additionally, SEE-E predicts microbreaks, suggesting depletion and a need for recovery (Kim et al., 2018). These results were anticipated due to the threat to resources SEE-E likely represents and the resource loss these elicitations likely cause. Meanwhile, SEE-I predicts more desirable behaviors and attitudes (e.g., job satisfaction, work engagement, and OCB), providing support for the idea that these elicitations bestow valuable resources to recipients. Curiously, akin to SEE-I, SEE-E was found to be predictive of OCB in our partial correlation analyses $\left(r_{1}=.24, p<.01\right)$. We did not expect this due to the stressor-esque nomological network of the SEE-E construct. This is perhaps less surprising on second thought, because - as demonstrated in our path analysis and partial correlation tests - the likely response to SEE (including SEE-E), is the provision of support — behaviors captured by OCB inventories.

We took an exploratory approach to the question: to what extent are the detrimental outcomes of SEE explained by the provision of support? Through our path analysis, we found significant direct effects of SEE-E and SEE-I on the provision of support, as well as abusive work behavior, production deviance, and withdrawal, with relations mirroring those found throughout this research (i.e., SEE-E being more negative than SEE-I). We also found significant direct effects of the provision of support on these same behaviors. More interestingly, however, 
were the indirect effects of both SEE-E and SEE-I on abusive work behavior, production deviance, and withdrawal—all of which were significant and positive through the provision of support. We see here that although SEE is related to a desirable outcome (a support response), it may contribute to resource loss for those who are solicited for and provide the support, potentially leading to undesirable emotion-focused coping behaviors (i.e., withdrawal and production deviance; e.g., Krischer et al., 2010) and abusive behavior at work, in line with COR theory (Hobfoll et al., 2018). This adds further evidence, however, for the distinction between SEE dimensions. That is, direct (and total) effects of SEE-E and SEE-I generally remained significant in the expected direction and magnitude after accounting for providing support.

\section{General Discussion}

Our study aimed to refine and expand the measurement and conceptualization of social burden. Specifically, we developed a measure of support elicitation experiences that differentiates between emotionally laden and instrumental requests for support. In addition, we sought to determine whether being elicited for support is uniformly detrimental, as suggested by social burden research. Across two studies, we find that expanding the scope of the support elicitation construct space to delineate instrumental from emotionally laden elicitations demonstrates that there are often differential effects based on the kind of elicitation. In Study 1, we found that SEE-E was primarily responsible for the strong relation to CWB found in past research on social burden (e.g., Gallagher \& Hughes, 2020; Yang et al., 2016). That is, although SEE-I correlated with production deviance and withdrawal, the explained variance in such behaviors was subsumed by SEE-E in our tests of incremental prediction. Study 2 yielded similar results; while SEE-I correlated with a mix of positive (e.g., work engagement) and negative (e.g., perpetrated abuse) outcomes, when partialling out the variance of SEE-E, SEE-I was uniformly 
related to positive outcomes (e.g., job satisfaction, reduced production deviance) and SEE-E was related to uniformly negative outcomes (e.g., abuse, production deviance). These correlational findings, both zero-order and partial, suggest that the multidimensional model is warranted.

We also found some evidence that providing support to instances of SEE can lead to negative outcomes, although the indirect effects did not fully explain the direct effects ${ }^{3}$. The indirect effects observed from both kinds of SEE on withdrawal, production deviance, and abusive work behaviors through the provision of support indicates that although employees may be likely to provide support to instances of SEE-E and SEE-I, the provision of support has the potential to contribute to resource loss, leading to undesirable behavior. This finding contributes to, and puts in new light, research on citizenship or helping pressure. Studies in this area examine the "dark side" of OCB, where pressure to help is typically conceived as coming from the organization (Koopman et al., 2020). Our findings suggest that OCB in response to SEE might be interpreted as similarly pressured, perhaps on a dyadic level, rather than an organizational level. In addition, the positive indirect effects from SEE-I, an experience we found to be generally positive, to our detrimental outcomes through support provision indicate a doubleedged sword of resource investment. That is, although those who experience SEE-I may, as hypothesized and observed in Study 2, invest these resources into others via OCB (support provision, in this case), this may be done at the expense of personal resources such as time (Hobfoll, 1989). Depletion of these resources would then lead to the outcomes seen here. We interpret the findings in the present research such that SEE-E is the more harmful experience, but both SEE-E and SEE-I, when paired with high acquiescence to support requests, may also lead to undesirable outcomes. It is likely that the two types of experiences work

\footnotetext{
${ }^{3}$ We note that an indirect effect in cross-sectional data does not constitute mediation, although, it is consistent with mediation.
} 
through different mechanisms. As rationalized earlier, SEE-E seems likely to contribute to strain via the potential for resource loss. Indeed, the potential support response for these behaviors has the potential to contribute to discomfort and negative emotions, as well as emotional labor on the part of the provider to meet the employee in emotional need with kindness and care. This potential for resource loss could transition to actual resource loss when support is given, potentially leading to deviant acts. High SEE-E might reflect the work environment as well. Consider a workplace filled with highly positive emotional scenes; if people were routinely exposed to expressions of positive affect (e.g., happiness, joy, or excitement), that might indicate a healthy workplace, routinely facilitating its members' positive outcomes. Conversely, an environment leading its employees to often display frustration or anger might be one that facilitates failure, an environment that would likely lead to many of the outcomes here. It is, perhaps, these many potential paths through which SEE-E could lead to detrimental outcomes that finds it so predictive of undesirable workplace outcomes in our studies.

On the other hand, SEE-I, particularly in isolation, does not appear to relate to negative outcomes readily. Prior research has indicated that being sought for and engaging in instrumental support contributes to feelings of cooperation and competence (Sonnentag, 2000), and these feelings are likely to contribute to resources for those being sought, resources they can, in turn, invest into their work, colleagues, and organization. In addition, it could be that SEE-I represents an unambiguous request, in contrast to the ambiguity often present with SEE-E; ambiguity is often cited as a driver for the detrimental effects of workplace exchanges such as incivility (e.g., Cortina et al., 2001). In fact, SEE-I might be indicative of a healthy workplace with collaborative employees, comfortable seeking work-related help. Findings in Study 2, however, suggest that in some cases, SEE-I is also related to undesirable work behavior such as instances of repeated 
support provision in response to SEE-I. Employees who feel highly pressured by their workplace to engage in helping behaviors have been shown to experience more negative affect (Koopman et al., 2020), so such a pressuring environment might make instances of SEE-I more difficult to deny, leading to fatigue, lower satisfaction, and more.

\section{Limitations and Future Research Directions}

The limitations of these studies can be seen as opportunities for future studies examining elicitations of social support from this understudied perspective. To begin, both studies relied on self-report data from Amazon's Mechanical Turk and used cross-sectional designs. While selfreport data is not inherently invalid (Chan, 2008), we cannot rule out the possibility of common method bias (Podsakoff et al., 2003) or the potential that participants responded dishonestly (Podsakoff \& Organ, 1986). The cross-sectional nature of our research also limits our ability to draw causal conclusions. Our findings should also be considered in light of the strengths and limitations posed by data collections through MTurk. For example, although MTurk samples are certainly more diverse than student or single organizational samples in terms of occupation, education, and age, they are also not representative of the general population in the United States (or elsewhere; Keith et al., 2017). Moreover, while the validity of data collected from MTurk has been supported across a number of studies (for reviews of this research see Cheung et al., 2017; Keith et al., 2017), care must be taken to ensure data quality including setting qualifications, attention checks, and appropriate data screening procedures as conducted in our studies. Such design limitations could be addressed in future research using multiple timepoints, collecting other-reports, and carefully considering confounding variables. For example, researchers may consider conducting research in an organizational setting where both parties' perceptions of SEE capture the full range of social exchanges. Alternatively, an experience sampling study (see 
Fisher \& To, 2012) would better examine how frequent exposure to SEE impacts both provision of support and outcomes including stress and burnout.

Although our study provides a refinement of Yang et al.'s measure, the two dimensions of SEE can only be interpreted in light of the item pool used to derive them. Indeed, our measure of SEE, although more robust than its predecessor, could be expanded to capture yet more situations and experiences in which people elicit support from their co-workers. Future work could expand on our measure to capture nuances in SEE that are unrepresented in the current scales.

Additionally, we made measurement decisions that should be considered somewhat limiting. The Abusive Work Behavior scale used in Study 2 was a shortened version of the larger abuse subscale found in the 32-item CWB-C (Spector et al., 2006). Although this measure demonstrated satisfactory reliability and criterion-related validity, we were unable to empirically test the statistical differences between the full-length abuse subscale and our shortened version in this study. Findings mirrored those of Study 1, however, which employed the full-length abuse scale. Further, we inferred provision of support rather than assess it directly. The OCB items were matched for content to bolster confidence, but it is a limitation, nonetheless. Similarly, our inferred provision of support only captures a portion of SEE's experiences. This limitation could be addressed in future research via dyadic research that captures SEE and provision explicitly from members in the social exchange.

Finally, future research is needed to examine the mediating mechanisms described in our hypothesis development, as well as how the source of SEE may impact outcomes. Although our results are consistent with logic of COR theory regarding resource threats, resource gains and investments, and the protecting of resources (e.g., Hobfoll 2001; Hobfoll et al., 2018), the 
theory's propositions leading to our hypotheses were not explicitly tested. For example, we propose that potential support providers will differentially evaluate the potential support response for SEE-I and SEE; this was not, however, formally tested. Future research is needed to examine these and other potential mechanisms (e.g., emotional labor) to provide a strong test of theory. Additionally, social support research emphasizes how source impacts the effects of social support (e.g., Sias \& Bartoo, 2007). Whether SEE stems from one's ingroup versus outgroup, a supervisor versus colleague, or coworker versus friend may have an impact on how SEE is experienced. From the perspective of the potential support provider, Yang et al. (2016) found that social burden from supervisors resulted in lower job satisfaction and higher turnover intentions compared to social burden from coworkers; social burden from coworkers resulted in higher anxiety and irritation compared to social burden from supervisors. As noted previously, the negative valence of the social burden items may have obscured the positive aspects of support elicitation from coworkers and supervisors. We speculate that supervisors may be less likely than coworkers to elicit emotional support and some support elicited from supervisors may signal trust or perceived competence. Likewise, SEE from coworkers is more likely to be both instrumental and emotional in nature; SEE-E from coworkers, however, may be less compatible with one's essential job tasks. We view this as a promising avenue for future research.

\section{Conclusion}

In this paper, we sought to refine and expand the measurement of social burden, thus broadening the nomological network of the support elicitation construct space. Findings from this study indicate that our measure of SEE appears to be an improvement over the scale previously used to measure the concept (i.e., Yang et al., 2016). Moreover, our findings challenge the prior notion that exposure to support elicitation is strictly associated with negative 
outcomes and suggest that it is emotionally laden requests for support that are associated with such outcomes, but requests for instrumental support are related to more desirable job attitudes. We believe that this study is a valuable contribution to the social support literature, as it deals with an angle of support often not studied (i.e., those who are put in a position to provide support) and demonstrates that there are differential effects for the kinds of support requested at work. 


\section{References}

American Educational Research Association (Ed.). (2011). Report and recommendations for the reauthorization of the institute of education sciences. American Educational Research Association.

Anderson, J. C., \& Gerbing, D. W. (1991). Predicting the performance of measures in a confirmatory factor analysis with a pretest assessment of their substantive validities. Journal of Applied Psychology, 76(5), 732. https://doi.org/10.1037/0021-9010.76.5.732

Axelrod, R. (1984). The evolution of cooperation. Basic Books.

Bandiera, O., Barankay, I., \& Rasul, I. (2009). Social connections and incentives in the workplace: Evidence from personnel data. Econometrica, 77(4), 1047-1094. http://doi.wiley.com/10.3982/ECTA6496

Barrera, M. (1986). Distinctions between social support concepts, measures, and models. American Journal of Community Psychology, 14(4), 413-445. https://doi.org/10.1007/BF00922627

Barrera, M., Sandler, I. N., \& Ramsay, T. B. (1981). Preliminary development of a scale of social support: Studies on college students. American Journal of Community Psychology, 9(4), 435-447. https://doi.org/10.1007/BF00918174

Basch, J., \& Fisher, C. D. (2000). Affective events-emotions matrix: A classification of work events and associated emotions. In N. Ashkanasy, C. Hartel, \& W. Zerbe (Eds.), Emotions in the workplace: Research, theory, and practice (pp. 36-48). Quorum.

Beehr, T. A., King, L. A., \& King, D. W. (1990). Social support and occupational stress: Talking to supervisors. Journal of Vocational Behavior, 36(1), 61-81. https://doi.org/10.1016/0001-8791(90)90015-T 
Bentler, P. M. (1990). Comparative fit indexes in structural models. Psychological Bulletin, 107(2), 238. https://doi.org/10.1037/0033-2909.107.2.238

Bledow, R., Schmitt, A., Frese, M., \& Kühnel, J. (2011). The affective shift model of work engagement. Journal of Applied Psychology, 96(6), 1246-1257. https://doi.org/10.1037/a0024532

Brotheridge, C. M., \& Grandey, A. A. (2002). Emotional Labor and Burnout: Comparing Two Perspectives of "People Work." Journal of Vocational Behavior, 60(1), 17-39. https://doi.org/10.1006/jvbe.2001.1815

Budner, S. B. (1962). Intolerance of ambiguity as a personality variable. Journal of Personality, $30(1), 29-50$.

Caplan, G. (1974). Support systems and community mental health: Lectures on concept development (pp. xvii, 267). Behavioral Publications.

Caplan, G., Killilea, M., \& Abrahams, R. B. (1976). Support systems and mutual help: Multidisciplinary explorations. Grune \& Stratton.

Caplan, R. D., Cobb, S., French, J. R., Harrison, R. U., \& Pinneau, S. R. (1975). Job demands and work health. In U.S. Department of Health, Education, and Welfare Publication No.75-160.

Chan, D. (2008). So why ask me? Are self-report data really that bad? In Statistical and Methodological Myths and Urban Legends (1st ed., pp. 329-356). Routledge. https://doi.org/10.4324/9780203867266-22

Chau, S. L., Dahling, J. J., Levy, P. E., \& Diefendorff, J. M. (2009). A predictive study of emotional labor and turnover. Journal of Organizational Behavior, 30(8), 1151-1163. https://doi.org/10.1002/job.617 
Cheung, J. H., Burns, D. K., Sinclair, R. R., \& Sliter, M. (2016). Amazon Mechanical Turk in Organizational Psychology: An Evaluation and Practical Recommendations. Journal of Business and Psychology, 32(4), 347-361. https://doi.org/10.1007/s10869-016-9458-5

Clark, L. A., \& Watson, D. (1995). Constructing validity: Basic issues in objective scale development. Psychological Assessment, 7(3), 309.

Clark, L. A., \& Watson, D. (2019). Constructing validity: New developments in creating objective measuring instruments. Psychological Assessment. https://doi.org/10.1037/pas0000626

Colquitt, J. A., Sabey, T. B., Rodell, J. B., \& Hill, E. T. (2019). Content validation guidelines: Evaluation criteria for definitional correspondence and definitional distinctiveness. Journal of Applied Psychology, 104(10), 1243. https://doi.org/10.1037/ap10000406

Cortina, L. M., Magley, V. J., Williams, J. H., \& Langhout, R. D. (2001). Incivility in the workplace: Incidence and impact. Journal of Occupational Health Psychology, 6(1), 64. https://doi.org/10.1037/1076-8998.6.1.64

Cumming, G. (2014). The new statistics: Why and how. Psychological Science, 25(1), 7-29.

Demerouti, E., Bakker, A. B., Nachreiner, F., \& Schaufeli, W. B. (2001). The job demandsresources model of burnout. Journal of Applied Psychology, 86(3), 499. https://doi.org/10.1037/0021-9010.86.3.499

Dignam, J. T., \& West, S. G. (1988). Social support in the workplace: Tests of six theoretical models. American Journal of Community Psychology, 16(5), 701-724.

Ekman, P., \& Friesen, W. V. (1975). Unmasking the face. Prentice-Hall. 
Ferguson, M. (2012). You cannot leave it at the office: Spillover and crossover of coworker incivility. Journal of Organizational Behavior, 33(4), 571-588. https://doi.org/10.1002/job.774

Fischer, E. H., \& Cohen, S. L. (1972). Demographic correlates of attitude toward seeking professional psychological help. Journal of Consulting and Clinical Psychology, 39(1), 70. https://doi.org/10.1037/h0033152

Fisher, C. D., \& To, M. L. (2012). Using experience sampling methodology in organizational behavior. Journal of Organizational Behavior, 33(7), 865-877. https://doi.org/10.1002/job.1803

Fox, S., Spector, P. E., Goh, A., Bruursema, K., \& Kessler, S. R. (2012). The deviant citizen: Measuring potential positive relations between counterproductive work behaviour and organizational citizenship behaviour. Journal of Occupational and Organizational Psychology, 85(1), 199-220. https://doi.org/10.1111/j.2044-8325.2011.02032.x

Freedson, P., Bowles, H. R., Troiano, R., \& Haskell, W. (2012). Assessment of physical activity using wearable monitors: Recommendations for monitor calibration and use in the field. Medicine \& Science in Sports \& Exercise, 44, S1-S4. https://doi.org/10.1249/MSS.0b013e3182399b7e

French, K. A., Dumani, S., Allen, T. D., \& Shockley, K. M. (2018). A meta-analysis of workfamily conflict and social support. Psychological Bulletin, 144(3), 284. https://doi.org/10.1037/bu10000120

Gallagher, C. M., \& Hughes, I. M. (2020). Bearing the burden: Outcomes and moderators of social burden in the workplace. Occupational Health Science, 4, 123-138. https://doi.org/10.1007/s41542-020-00063-4 
Hair Jr., J. F., Black, W. C., Babin, B. J., \& Anderson, R. E. (2010). Multivariate data analysis: A global perspective. Pearson Education.

Halbesleben, J. R. B., Neveu, J.-P., Paustian-Underdahl, S. C., \& Westman, M. (2014). Getting to the "COR": Understanding the role of resources in conservation of resources theory. Journal of Management, 40(5), 1334-1364. https://doi.org/10.1177/0149206314527130

Halbesleben, J. R. B., \& Wheeler, A. R. (2015). To Invest or Not? The Role of Coworker Support and Trust in Daily Reciprocal Gain Spirals of Helping Behavior. Journal of Management, 41(6), 1628-1650. https://doi.org/10.1177/0149206312455246

Hayes, A. F. (2013). Introduction to mediation, moderation, and conditional process analysis: A regression-based approach. The Guilford Press.

Hinkin, T. R., \& Tracey, J. B. (1999). An analysis of variance approach to content validation. Organizational Research Methods, 2(2), 175-186. https://doi.org/10.1177/109442819922004

Hobfoll, S. E. (1989). Conservation of resources: A new attempt at conceptualizing stress. American Psychologist, 513-524.

Hobfoll, S. E. (2001). The Influence of Culture, Community, and the Nested-Self in the Stress Process: Advancing Conservation of Resources Theory. Applied Psychology, 50(3), 337421. https://doi.org/10.1111/1464-0597.00062

Hobfoll, S. E., Halbesleben, J., Neveu, J.-P., \& Westman, M. (2018). Conservation of Resources in the Organizational Context: The Reality of Resources and Their Consequences. Annual Review of Organizational Psychology and Organizational Behavior, 5(1), 103-128. https://doi.org/10.1146/annurev-orgpsych-032117-104640 
Hobfoll, S., Johnson, R., Ennis, N., \& Jackson, A. (2003). Resource Loss, Resource Gain, and Emotional Outcomes Among Inner City Women. Journal of Personality and Social Psychology, 84, 632-643. https://doi.org/10.1037/0022-3514.84.3.632

Hulland, J. (1999). Use of partial least squares (PLS) in strategic management research: A review of four recent studies. Strategic Management Journal, 20(2), 195-204. https://doi.org/10.1002/(SICI)1097-0266(199902)20:2<195::AID-SMJ13>3.0.CO;2-7

Hülsheger, U. R., \& Schewe, A. F. (2011). On the costs and benefits of emotional labor: A metaanalysis of three decades of research. 16(3), 361-389.

Hunt, J., \& Eisenberg, D. (2010). Mental Health Problems and Help-Seeking Behavior Among College Students. Journal of Adolescent Health, 46(1), 3-10. https://doi.org/10.1016/j.jadohealth.2009.08.008

Jolly, P. M., Kong, D. T., \& Kim, K. Y. (2020). Social support at work: An integrative review. Journal of Organizational Behavior, n/a(n/a). https://doi.org/10.1002/job.2485

Kahn, W. A. (1990). Psychological Conditions of Personal Engagement and Disengagement at Work. The Academy of Management Journal, 33(4), 692-724. JSTOR. https://doi.org/10.2307/256287

Keith, M. G., Tay, L., \& Harms, P. D. (2017). Systems Perspective of Amazon Mechanical Turk for Organizational Research: Review and Recommendations. Frontiers in Psychology, 8. https://doi.org/10.3389/fpsyg.2017.01359

Kelly, J., \& Barsade, S. (2001). Mood and Emotions in Small Groups and Work Teams. Organizational Behavior and Human Decision Processes, 86, 99-130. https://doi.org/10.1006/obhd.2001.2974 
Kim, S., Park, Y., \& Headrick, L. (2018). Daily micro-breaks and job performance: General work engagement as a cross-level moderator. Journal of Applied Psychology, 103(7), 772-786. https://doi.org/10.1037/ap10000308

Kim, S., Park, Y., \& Niu, Q. (2017). Micro-break activities at work to recover from daily work demands. Journal of Organizational Behavior, 38(1), 28-44. https://doi.org/10.1002/job.2109

Kline, R. B. (2015). Principles and Practice of Structural Equation Modeling, Fourth Edition. Guilford Publications.

Koopman, J., Rosen, C. C., Gabriel, A. S., Puranik, H., Johnson, R. E., \& Ferris, D. L. (2020). Why and for whom does the pressure to help hurt others? Affective and cognitive mechanisms linking helping pressure to workplace deviance. Personnel Psychology, 73(2), 333-362. https://doi.org/10.1111/peps.12354

Krischer, M. M., Penney, L. M., \& Hunter, E. M. (2010a). Can counterproductive work behaviors be productive? CWB as emotion-focused coping. Journal of Occupational Health Psychology, 15(2), 154-166. https://doi.org/10.1037/a0018349

Krischer, M. M., Penney, L. M., \& Hunter, E. M. (2010b). Can counterproductive work behaviors be productive? CWB as emotion-focused coping. Journal of Occupational Health Psychology, 15(2), 154-166. https://doi.org/10.1037/a0018349

Lane, M. S., \& Klenke, K. (2004). The ambiguity tolerance interface: A modified social cognitive model for leading under uncertainty. Journal of Leadership \& Organizational Studies, 10(3), 69-81. https://doi.org/10.1177/107179190401000306 
Lim, S., \& Lee, A. (2011). Work and nonwork outcomes of workplace incivility: Does family support help? Journal of Occupational Health Psychology, 16(1), 95-111. https://doi.org/10.1037/a0021726

MacCallum, R. C., Browne, M. W., \& Sugawara, H. M. (1996). Power analysis and determination of sample size for covariance structure modeling. Psychological Methods, 1(2), 130. https://doi.org/10.1037/1082-989X.1.2.130

Marcus, B., Taylor, O. a, Hastings, S. E., Sturm, A., \& Weigelt, O. (2016). The structure of counterproductive work behavior: A review, a structural meta-analysis, and a primary study. Journal of Management, 42(1), 203-233.

Matthews, R. A., \& Ritter, K.-J. (2016). A concise, content valid, gender invariant measure of workplace incivility. Journal of Occupational Health Psychology, 21(3), 352-365. https://doi.org/10.1037/ocp0000017

McDonald, R. P. (1999). Test theory: A unified treatment. Lawrence Erlbaum Associates Publishers.

Miller, V. D., \& Jablin, F. M. (1991). Information Seeking during Organizational Entry: Influences, Tactics, and a Model of the Process. The Academy of Management Review, 16(1), 92-120. https://doi.org/10.2307/258608

Morrison, E. W. (2002). Information Seeking Within Organizations. Human Communication Research, 28(2), 229-242. https://doi.org/10.1111/j.1468-2958.2002.tb00805.x

Muthén, L. K., \& Muthén, B. (2015). Mplus. The comprehensive modelling program for applied researchers: User's guide, 5. 
Olson, M. (1989). Collective Action. In J. Eatwell, M. Milgate, \& P. Newman (Eds.), The Invisible Hand (pp. 61-69). Palgrave Macmillan UK. https://doi.org/10.1007/978-1-34920313-0_5

Organ, D. W. (1997). Organizational citizenship behavior: It's construct clean-up time. Human Performance, 10(2), 85-97. https://doi.org/10.1207/s15327043hup1002_2

Podsakoff, P. M., MacKenzie, S. B., Lee, J.-Y., \& Podsakoff, N. P. (2003). Common method biases in behavioral research: A critical review of the literature and recommended remedies. Journal of Applied Psychology, 88(5), 879. https://doi.org/10.1037/00219010.88 .5 .879

Podsakoff, P. M., MacKenzie, S. B., Moorman, R. H., \& Fetter, R. (1990). Transformational leader behaviors and their effects on followers' trust in leader, satisfaction, and organizational citizenship behaviors. The Leadership Quarterly, 1(2), 107-142.

Podsakoff, P. M., \& Organ, D. W. (1986). Self-Reports in Organizational Research: Problems and Prospects. Journal of Management, 12(4), 531-544.

https://doi.org/10.1177/014920638601200408

Quinn, R., \& Shepard, L. (1974). The 1972-73 Quality of Employment Survey. Descriptive Statistics, with Comparison Data from the 1969-70 Survey of Working Conditions.

Rosseel, Y. (2012). lavaan: An R package for structural equation modeling and more Version 0.5-12 (BETA). 37.

Sakurai, K., \& Jex, S. M. (2012). Coworker incivility and incivility targets' work effort and counterproductive work behaviors: The moderating role of supervisor social support. Journal of Occupational Health Psychology, 17(2), 150-161.

https://doi.org/10.1037/a0027350 
Saunders, S. M., Resnick, M. D., Hoberman, H. M., \& Blum, R. W. (1994). Formal HelpSeeking Behavior of Adolescents Identifying Themselves as Having Mental Health Problems. Journal of the American Academy of Child \& Adolescent Psychiatry, 33(5), 718-728. https://doi.org/10.1097/00004583-199406000-00013

Schaufeli, W. B., \& Bakker, A. B. (2004). Job demands, job resources, and their relationship with burnout and engagement: A multi-sample study. Journal of Organizational Behavior, 25(3), 293-315. https://doi.org/10.1002/job.248

Schaufeli, W. B., Salanova, M., Lez-Roma, V. G., \& Bakker, A. B. (2002). The measurement of engagment and burnout: A two sample confirmatory factor analytic approach. Journal of Happiness Studies, 3(1), 71-92.

Shaffer, J. A., DeGeest, D., \& Li, A. (2016). Tackling the Problem of Construct Proliferation: A Guide to Assessing the Discriminant Validity of Conceptually Related Constructs. Organizational Research Methods, 19(1), 80-110. https://doi.org/10.1177/1094428115598239

Sias, P., \& Bartoo, H. (2007). Friendship, Social Support, and Health. In Low-Cost Approaches to Promote Physical and Mental Health: Theory, Research, and Practice (pp. 455-472). https://doi.org/10.1007/0-387-36899-X_23

Sias, P. M. (2009). Organizing relationships: Traditional and emerging perspectives on workplace relationships. SAGE.

Sonnentag, S. (2000). Excellent Performance: The Role of Communication and Cooperation Processes. Applied Psychology, 49(3), 483-497. https://doi.org/10.1111/14640597.00027 
Spector, Paul E., Fox, S., Penney, L. M., Bruursema, K., Goh, A., \& Kessler, S. (2006). The dimensionality of counterproductivity: Are all counterproductive behaviors created equal? Journal of Vocational Behavior, 68(3), 446-460. https://doi.org/10.1016/j.jvb.2005.10.005

Spector, P.E., Bauer, J. A., \& Fox, S. (2010). Measurement artifacts in the assessment of counterproductive work behavior and organizational citizenship behavior: Do we know what we think we know? The Journal of Applied Psychology, 95(4), 781-790. https://doi.org/10.1037/a0019477

Steiger, J. H. (1990). Structural Model Evaluation and Modification: An Interval Estimation Approach. Multivariate Behavioral Research, 25(2), 173-180. https://doi.org/10.1207/s15327906mbr2502_4

Stryker, S., \& Statham, A. (1985). Symbolic interactionism and role theory. In G. Lindzey \& E. Aronson (Eds.), The handbook of social psychology (pp. 311-378). Random House.

Stryker, S., \& Vryan, K. D. (2006). The symbolic interactionist frame. In Handbook of social psychology (pp. 3-28). Springer.

Tabachnick, B. G., Fidell, L. S., \& Ullman, J. B. (2007). Using Multivariate Statistics (Vol. 5). Pearson.

Taylor, S. E. (2002). The Tending Instinct: How Nurturing is Essential to Who We Are and How We Live. Macmillan.

Thomas, K. A., \& Clifford, S. (2017). Validity and mechanical turk: An assessment of exclusion methods and interactive experiments. Computers in Human Behavior, 77, 184-197. 
Viswesvaran, C., Sanchez, J. I., \& Fisher, J. (1999). The role of social support in the process of work stress: A meta-analysis. Journal of Vocational Behavior, 54(2), 314-334. https://doi.org/10.1006/jvbe.1998.1661

Westman, M., \& Eden, D. (1997). Effects of a respite from work on burnout: Vacation relief and fade-out. Journal of Applied Psychology, 82(4), 516-527. https://doi.org/10.1037/00219010.82 .4 .516

Yang, L. Q. (2009). Aggression and its consequences in nursing: A more complete story by adding its social context [Doctoral dissertation].

Yang, L.-Q., Liu, C., Nauta, M. M., Caughlin, D. E., \& Spector, P. E. (2016). Be mindful of what you impose on your colleagues: Implications of social burden for burdenees' wellbeing, attitudes and counterproductive work behaviour: Social burden in the workplace. Stress and Health, 32(1), 70-83. https://doi.org/10.1002/smi.2581 


\section{Figure 1}

Parallel Analysis of Support Elicitation/Social Burden Items

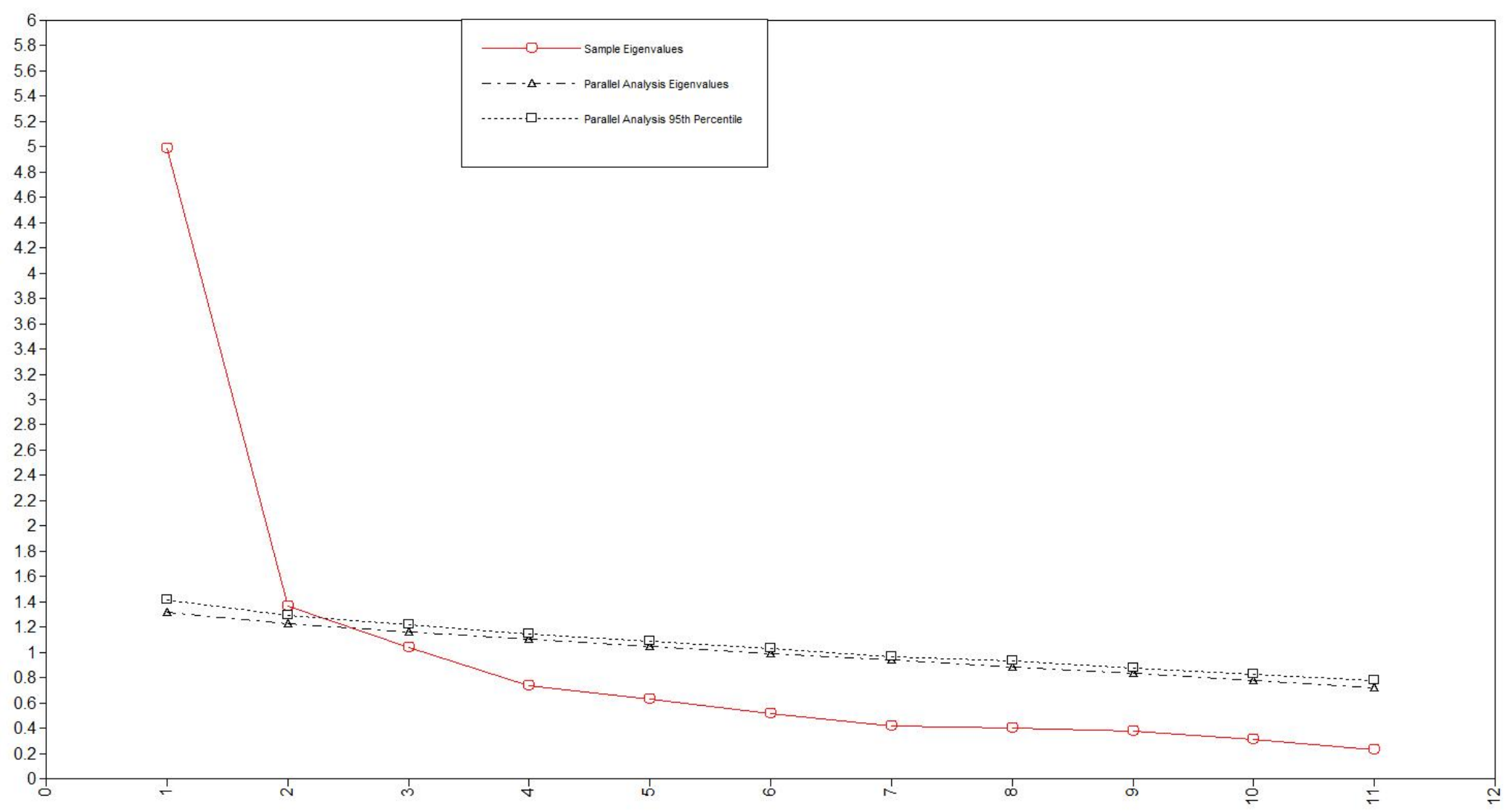




\section{Figure 2}

Path model of SEE, Inferred Provision of Support, and CWB

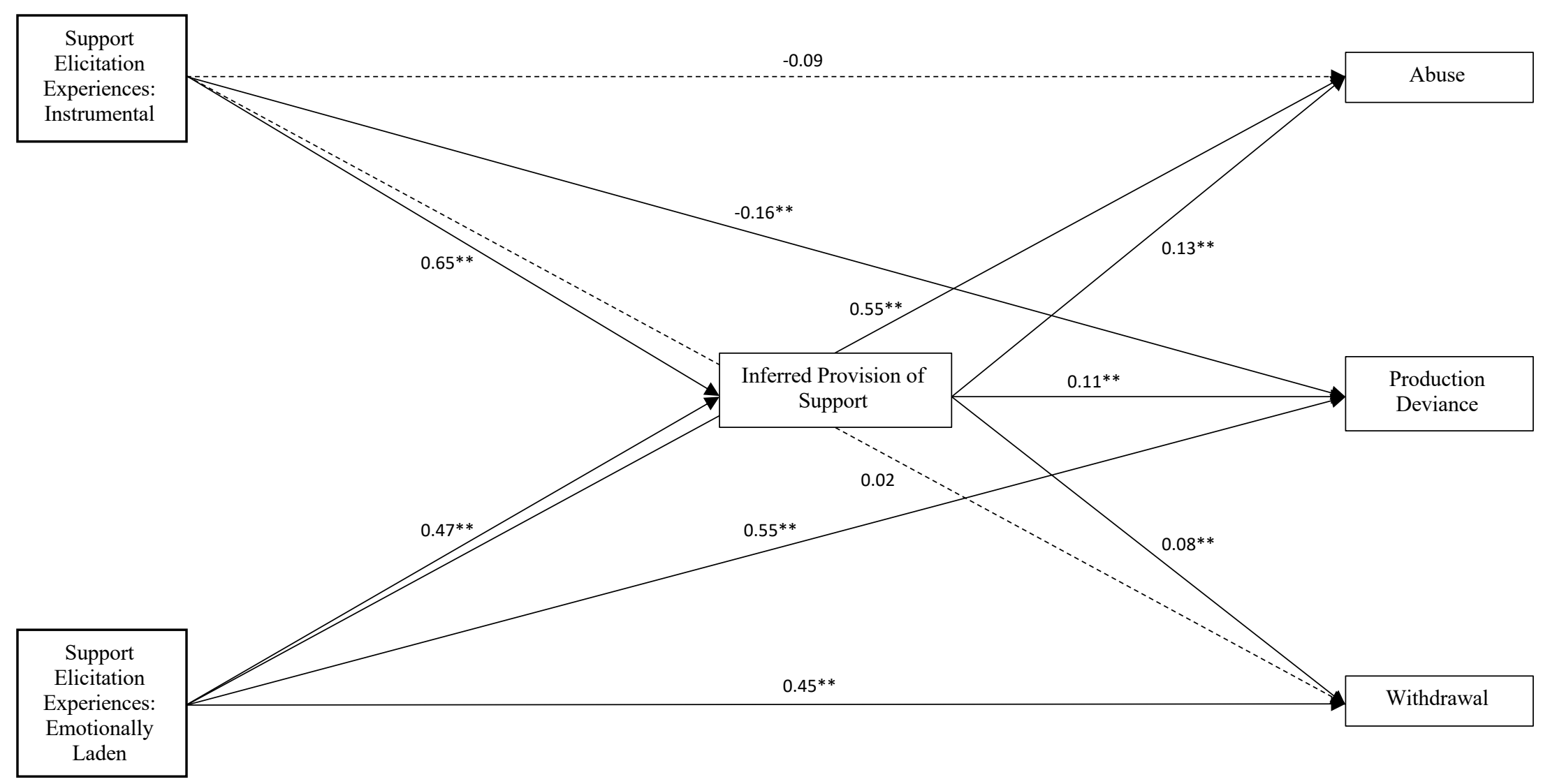

Note. $*=p<.05, * *=p<.01$ 


\section{Table 1}

Item pool for SME ratings

\begin{tabular}{llll}
\hline Item number and item & htc & $M$ & $S D$ \\
\hline
\end{tabular}

\section{Original Yang et al. (2016) Items}

1. Acted emotionally upset in my presence (not towards me)*

2. Wanted me to take care of their work responsibilities*

3. Asked me to do something for them in the middle of my work*

4. Lost their temper in my presence (not towards me)*
$0.69 \quad 4.86 \quad 1.73$

$0.67 \quad 4.71 \quad 2.02$

$\begin{array}{lll}0.80 & 5.57 \quad 1.40\end{array}$

$\begin{array}{lll}0.56 & 3.93 & 1.49\end{array}$

\section{New Items Created for Scale Development}

5. Told me about an issue that was private or emotionally difficult to discuss*

6. Expressed doubt about their work or nonwork abilities*

7. Explicitly asked for approval of their behavior*

8. Asked me for work-related advice*

9. Asked me to provide feedback on a piece of their work*

10. Asked for help outside of work (for example a ride or a loan)*

11. Asked me to explain how something works*

12. Asked me to leave a good word for them

13. Complained about home or family life to me

14. Asked me to make personal—not professional—introductions

15. Asked me to an unscheduled lunch during the workday

16. Complained of boredom in my presence or toward me

17. Engaged in extended non-work-related conversations

$0.44 \quad 3.07$

Note. SMEs $(N=14)$ rated based on question "How well do you think the items represent the construct described above?"

* - items retained for data collection. htc: Hinkin \& Tracey correspondence index 
Table 2

Exploratory Factor Analysis of Support Elicitation Items

\begin{tabular}{lccc}
\hline Items & $h^{2}$ & Emotionally Laden & Instrumental \\
\hline 1 & 0.44 & 0.70 & \\
2 & 0.29 & 0.51 & \\
3 & 0.41 & 0.49 & \\
4 & 0.55 & 0.83 & \\
5 & 0.62 & 0.78 & \\
6 & 0.41 & 0.52 & 0.86 \\
7 & 0.73 & & 0.81 \\
8 & 0.67 & & \\
9 & 0.31 & 0.49 & \\
10 & 0.55 & 0.66 & 0.57 \\
11 & 0.49 & & \\
\hline
\end{tabular}

Note. $N=299 . h^{2}=$ item communality.

Factor correlation $=.54$.

Factor loads $<.3$ suppressed from table. 


\section{Table 3}

Means, standard deviations, and correlations with confidence intervals

\begin{tabular}{|c|c|c|c|c|c|c|c|c|c|c|}
\hline Variable & $M$ & $S D$ & 1 & 2 & 3 & 4 & 5 & 6 & 7 & 8 \\
\hline 1. Social Burden & 2.18 & 0.80 & .76 & & & & & & & \\
\hline 2. SEE-I & 2.76 & 0.98 & $\begin{array}{c}.40^{* *} \\
{[.28, .51]}\end{array}$ & .81 & & & & & & \\
\hline 3. SEE-E & 2.02 & 0.82 & $\begin{array}{c}.84^{* *} \\
{[.79, .87]}\end{array}$ & $\begin{array}{c}.37^{* *} \\
{[.24, .49]}\end{array}$ & .79 & & & & & \\
\hline 4. Abuse & 1.36 & 0.06 & $\begin{array}{c}.43^{* *} \\
{[.31, .58]}\end{array}$ & $\begin{array}{c}.14 \\
{[-.01, .27]}\end{array}$ & $\begin{array}{c}.48^{* *} \\
{[.36, .58]}\end{array}$ & .96 & & & & \\
\hline 5. Production Deviance & 1.40 & 0.70 & $\begin{array}{c}.42^{* *} \\
{[.29, .53]}\end{array}$ & $\begin{array}{c}.16^{*} \\
{[.02, .30]}\end{array}$ & $\begin{array}{c}.46^{* *} \\
{[.34, .56]}\end{array}$ & $\begin{array}{c}.88^{* *} \\
{[.84, .91]}\end{array}$ & .86 & & & \\
\hline 6. Withdrawal & 1.77 & 0.73 & $\begin{array}{c}.40^{* *} \\
{[.27, .51]}\end{array}$ & $\begin{array}{c}.25^{* *} \\
{[.11, .38]}\end{array}$ & $\begin{array}{c}.43^{* *} \\
{[.31, .54]}\end{array}$ & $\begin{array}{c}.68^{* *} \\
{[.60, .75]}\end{array}$ & $\begin{array}{c}.69^{* *} \\
{[.61, .76]}\end{array}$ & .89 & & \\
\hline 7. Sabotage & 1.31 & .74 & $\begin{array}{c}.37^{* *} \\
{[.25, .49]}\end{array}$ & $\begin{array}{c}.10 \\
{[-.04, .24]}\end{array}$ & $\begin{array}{c}.43^{* *} \\
{[.31, .54]}\end{array}$ & $\begin{array}{c}.93^{* *} \\
{[.91, .94]}\end{array}$ & $\begin{array}{c}.86^{* *} \\
{[.82, .89]}\end{array}$ & $\begin{array}{c}.63^{* *} \\
{[.54, .71]}\end{array}$ & .76 & \\
\hline 8. Theft & 1.31 & 0.68 & $\begin{array}{r}.35^{* *} \\
{[.22, .47]}\end{array}$ & $\begin{array}{c}.07 \\
{[-.07, .21]}\end{array}$ & $\begin{array}{c}.42^{* *} \\
{[.30, .53]}\end{array}$ & $\begin{array}{c}.92^{* *} \\
{[.89, .94]}\end{array}$ & $\begin{array}{c}.83^{* *} \\
{[.78, .87]}\end{array}$ & $\begin{array}{c}.65^{* *} \\
{[.56, .72]} \\
\end{array}$ & $\begin{array}{c}.93^{* *} \\
{[.90, .94]} \\
\end{array}$ & .86 \\
\hline
\end{tabular}

Note. $N=192$. Values in square brackets indicate the $95 \%$ confidence interval for each correlation. The confidence interval is a plausible range of population correlations that could have caused the sample correlation. Omega values are in bold along the diagonal. SEE: Support Elicitation Experiences, I: Instrumental, E: Emotionally Laden

${ }^{*} p<.05,{ }^{* *} p<.01$. 


\section{Table 4}

Incremental Validity Analyses for Study 1

\begin{tabular}{|c|c|c|c|c|c|c|c|c|c|c|}
\hline \multirow{2}{*}{$\begin{array}{l}\text { Variables } \\
\text { Model }\end{array}$} & \multicolumn{2}{|c|}{ Abuse } & \multicolumn{2}{|c|}{$\begin{array}{l}\text { Production } \\
\text { Deviance }\end{array}$} & \multicolumn{2}{|c|}{ Withdrawal } & \multicolumn{2}{|c|}{ Sabotage } & \multicolumn{2}{|c|}{ Theft } \\
\hline & 1 & 2 & 1 & 2 & 1 & 2 & 1 & 2 & 1 & 2 \\
\hline Int. & $.62^{*}$ & $.64^{*}$ & $.60^{*}$ & $.58^{*}$ & $.99^{*}$ & $.81^{*}$ & $.56^{*}$ & $.60^{*}$ & $.67^{*}$ & $.73^{*}$ \\
\hline Social Burden & $.34^{*}(.43)$ & $.09(.12)$ & $.36^{*}(.42)$ & $.09(.10)$ & $.36^{*}(.40)$ & $.02(.03)$ & $.35^{*}(.38)$ & $.05(.06)$ & $.30^{*}(.35)$ & $.01(.02)$ \\
\hline SEE-I & & $-.01(-.02)$ & & $.01(.02)$ & & $.10(.14)$ & & $-.03(-.03)$ & & $-.04(-.06)$ \\
\hline SEE-E & & $.27^{*}(.38)$ & & $.30^{*}(.36)$ & & $.31^{*}(.37)$ & & $.33^{*}(.39)$ & & $.33^{*}(.43)$ \\
\hline$R^{2}$ & $.19^{*}$ & $.23^{*}$ & $.17^{*}$ & $.21^{*}$ & $.16^{*}$ & $.21^{*}$ & $.14^{*}$ & $.19^{*}$ & $.12^{*}$ & $.18^{*}$ \\
\hline$\Delta R^{2}$ & CI[.10,.28] & $\begin{array}{c}\mathrm{CI}[.12, .32] \\
.04^{*} \\
\mathrm{CI}[-.01, .09]\end{array}$ & CI $[.09, .27]$ & $\begin{array}{c}\mathrm{CI}[.11, .30] \\
.04^{*} \\
\mathrm{CI}[-.01, .09]\end{array}$ & CI $[.07, .25]$ & $\begin{array}{c}\mathrm{CI}[.10, .29] \\
.05^{*} \\
\mathrm{CI}[-.00, .11]\end{array}$ & CI $[.06, .23]$ & $\begin{array}{c}\mathrm{CI}[.09, .28] \\
.05^{*} \\
\mathrm{CI}[-.01, .10]\end{array}$ & CI $[.05, .21]$ & $\begin{array}{c}\text { CI[.08,.27] } \\
.06^{*} \\
\text { CI }[-.00, .12]\end{array}$ \\
\hline
\end{tabular}

Note. $N=192$; values outside parentheses represent unstandardized regression weights $(b)$; values in parentheses indicate the standardized regression weights $(\beta)$; Int. represents the Y-intercept in the unstandardized regression equations. Confidence intervals (CI) are at the 95\% level. SEE: Support Elicitation Experiences, I: Instrumental, E: Emotionally Laden.

${ }^{*} p<.01$ 


\section{Table 5}

OCB-C SME ratings for Inferred Provision of Support index

Item number and item Rating

1. Picked up meal for others at work. 1

2. Took time to advise, coach, or mentor a co-worker. * $\quad 5$

3. Helped co-worker learn new skills or shared job knowledge. * 5

4. Helped new employees get oriented to the job. 2

5. Lent a compassionate ear when someone had a work problem. 2.5

6. Lent a compassionate ear when someone had a personal problem. * 4.5

7. Changed vacation schedule, work days, or shifts to accommodate co-worker's needs. $\quad 1.5$

8. Offered suggestions to improve how work is done. $\quad 1$

9. Offered suggestions for improving the work environment. $\quad 1$

10. Finished something for a co-worker who had to leave early. $\quad 1$

11. Helped a less capable co-worker lift a heavy box or other object. 1

12. Helped a co-worker who had too much to do. 1

13. Volunteered for extra work assignments. 1

14. Took phone messages for absent or busy coworker. $\quad 1$

15. Said good things about your employer in front of others. 1

16. Gave up meal and other breaks to complete work. 1

17. Volunteered to help a co-worker deal with a difficult customer, vendor, or co-worker. $\quad 1.5$

18. Went out of the way to give co-worker encouragement or express appreciation. * 4

19. Decorated, straightened up, or otherwise beautified common work space. 1

20. Defended a co-worker who was being "put down" or spoken ill of by other co-workers or 4 supervisor. *

Note. SMEs $(N=2)$ rated based on question "How well do you think the items represent the provision of support to a SEE item?" * - item used for Inferred Provision of Support index. 
Table 6

SEE-I and SEE-E Bivariate and Partial Correlations for Study 2

\begin{tabular}{lcccccc}
\hline Variable & $M$ & $S D$ & $\begin{array}{c}\text { SEE-I bivariate } \\
\text { correlations }\end{array}$ & $\begin{array}{c}\text { SEE-I partial } \\
\text { correlations }\end{array}$ & $\begin{array}{c}\text { SEE-E bivariate } \\
\text { correlations }\end{array}$ & $\begin{array}{c}\text { SEE-E partial } \\
\text { correlations }\end{array}$ \\
\hline OCB & 3.17 & 1.08 & $\mathbf{0 . 4 6}$ & $\mathbf{0 . 3 0}$ & $\mathbf{0 . 3 6}$ & $\mathbf{0 . 2 4}$ \\
Abuse & 1.56 & 0.74 & $\mathbf{0 . 1 6}$ & -0.03 & $\mathbf{0 . 3 4}$ & $\mathbf{0 . 3 3}$ \\
Withdrawal & 1.86 & 0.79 & $\mathbf{0 . 1 0}$ & -0.05 & $\mathbf{0 . 2 5}$ & $\mathbf{0 . 2 4}$ \\
Production Deviance & 1.42 & 0.73 & 0.07 & $\mathbf{- 0 . 1 2}$ & $\mathbf{0 . 2 5}$ & $\mathbf{0 . 3 2}$ \\
Job Satisfaction & 3.43 & 0.61 & 0.04 & $\mathbf{0 . 1 2}$ & $\mathbf{- 0 . 1 0}$ & $\mathbf{- 0 . 2 1}$ \\
Work Engagement & 4.41 & 1.27 & $\mathbf{0 . 1 7}$ & $\mathbf{0 . 2 0}$ & -0.03 & $\mathbf{- 0 . 1 0}$ \\
Microbreaks & 2.85 & 0.70 & $\mathbf{0 . 1 8}$ & 0.06 & $\mathbf{0 . 2 5}$ & $\mathbf{0 . 1 8}$ \\
Provision & 3.28 & 1.19 & $\mathbf{0 . 5 0}$ & $\mathbf{0 . 3 6}$ & $\mathbf{0 . 3 7}$ & $\mathbf{0 . 2 2}$ \\
\hline
\end{tabular}

Note. $N=734$. OCB: Organizational Citizenship Behavior, SEE: Support Elicitation Experiences, I: Instrumental, E: Emotionally Laden; Provision: Inferred Provision of Support.

Correlations in bold indicate the value is statistically significant at $p<.01$. 
Table 7

Direct and Indirect Effects for Study 2 Path Analysis

\begin{tabular}{lcccc}
\hline Paths & Est. & $S E$ & $95 \%$ CI-L & $95 \%$ CI-U \\
\hline SEE-I - Abuse & -0.09 & 0.05 & -0.19 & 0.02 \\
SEE-I - PD & $-0.16^{* *}$ & 0.05 & -0.27 & -0.06 \\
SEE-I - WD & 0.02 & 0.05 & -0.13 & 0.08 \\
SEE-I - PS & $0.65^{* *}$ & 0.05 & 0.55 & 0.75 \\
SEE-E - Abuse & $0.55^{* *}$ & 0.06 & 0.41 & 0.68 \\
SEE-E - PD & $0.55^{* *}$ & 0.06 & 0.43 & 0.67 \\
SEE-E - WD & $0.45^{* *}$ & 0.06 & 0.34 & 0.58 \\
SEE-E - PS & $0.47^{* *}$ & 0.06 & 0.34 & 0.59 \\
PS - Abuse & $0.13^{* *}$ & 0.02 & 0.08 & 0.18 \\
PS - PD & $0.11^{* *}$ & 0.03 & 0.06 & 0.16 \\
PS - WD & $0.08^{* *}$ & 0.03 & 0.03 & 0.14 \\
SEE-I - PS - Abuse & $0.11^{* *}$ & 0.02 & 0.06 & 0.17 \\
SEE-I - PS - PD & $0.07^{* *}$ & 0.02 & 0.04 & 0.12 \\
SEE-I - PS - WD & $0.10^{* *}$ & 0.02 & 0.05 & 0.15 \\
SEE-E - PS - Abuse & $0.07^{* *}$ & 0.02 & 0.03 & 0.11 \\
SEE-E - PS - PD & $0.07^{* *}$ & 0.02 & 0.03 & 0.12 \\
SEE-E - PS - WD & $0.05^{* *}$ & 0.02 & 0.02 & 0.09 \\
\hline
\end{tabular}

Note. $N=734$. Standardized estimates (Est.) and confidence intervals (CI) calculated using 10,000 bias-correct bootstrapped samples (Hayes, 2013). Est: Standardized estimate; SE: Standard error; 95\% CI-L: Lower bound 95\% confidence interval; 95\% CI-U: Upper bound 95\% confidence interval. SEE: Support Elicitation Experiences, I: Instrumental, E: Emotionally Laden; PD: Production Deviance; WD: Withdrawal; PS: Inferred Provision of Support.

$*=p<.05, * *=p<.01$. 


\section{Appendix A Content Validation Study}

\section{Participants and Procedures}

39 SMEs were recruited to participate in our content validation study. Participants had an average of $7.27(S D=2.32)$ years of education post high-school and most $(48 \%)$ had moderate levels of familiarity with social support research. Participants completed an item-sorting task popularized by Anderson and Gerbing (1991) using Qualtrics software. In the task, participants were asked to match a set of items, comprising 4 different constructs, to definitions of the 4 constructs included in the item set. The measures included in this content validation study were selected due to varying degrees of conceptual overlap with the SEE construct. These orbiting constructs should be related to SEE but SEE should be distinct from these constructs. The measures and their respective construct definitions are elaborated upon in the following section. Definitions of the constructs below were elaborated if the scale authors did not provide a succinct definition. Furthermore, we opted to use a coworker referent for both SEE and incivility for consistency, as these scales do not have firm referents; that is, while we developed the SEE scale using a colleague (i.e., supervisor and coworker) referent, we anticipate the SEE scale will be adapted to be specific to supervisors or coworkers depending on the goal of researchers using our scale, similar to many incivility scales (e.g., Ferguson, 2012; Lim \& Lee, 2011; Sakurai \& Jex, 2012). Colleague and coworker, in addition, are often considered synonyms, and using the latter referent for both SEE and incivility likely allows for easier interpretation of items for potentially unfamiliar audiences. We did not modify the firm referents for the communications scale (supervisor) from Beehr et al. (1990) and the OCB-Altruism scale (no referent) from Podsakoff et al. (1990).

\section{Measures}


Support Elicitation Experiences. SEE, which was defined in this task as "Behaviors by coworkers where someone should offer help or be supportive," was measured using the measure developed in Study 1. We modified the definition for the SEE construct in this task to incorporate more plain language while retaining the same normative (i.e., "someone should") response element, in order to be more readable for potentially unfamiliar audiences. An example item was "[A coworker] asked me for work-related advice."

Affective Content of Communications with Supervisors. The affective content of communications with supervisors, defined in this task as "A form of social support that focuses on communication between an employee and their supervisor", was measured using a measured developed by Beehr and colleagues (1990). Items assess different topics of conversation employees may have with their supervisors (e.g., "My supervisor and I share personal information about our backgrounds and families").

Experienced Workplace Incivility. Experienced workplace incivility, defined in this task as "Low intensity behaviors by coworkers in which there is uncertainty as to whether they are trying to harm (e.g., insult) you", was measured using a measure workplace incivility created by Matthews and Ritter (2016). Items assess various behaviors one can experience from their colleagues on the job (e.g., "[A coworker] paid little attention to your statements or showed little interest in your opinions").

Altruism. OCB-Altruism, defined in this task as "When you help others at work without expectation of reward", was measured using the OCB-Altruism measure from Podsakoff and colleagues (1990). Items reflect a tendency to help others at work (e.g., "I help others who have heavy workloads").

\section{Results \& Discussion}


Definitional distinctiveness, per Anderson and Gerbing (1991), is calculated using both the proportion of standard agreement: $p_{s a}=\frac{n_{c}}{N}$, where $n_{c}$ represents the number of correct responses, and $N$ represents the total number of responses, as well the substantive-validity coefficient: $c_{s v}=\frac{n_{c}-n_{o}}{N}$, where $n_{c}$ again represents the number of correct responses and $N$ represents the total number of responses, but the this time $n_{o}$, or the number of assignments of an item to the most frequently assigned incorrect construct definition in the set, is subtracted from $n_{c}$ before being divided by $N$. Values for $p_{s a}$ range from 0 to 1 , with larger numbers indicating greater content validity, while values for $c_{s v}$ range from -1 to 1 , with larger positive numbers also indicating greater content validity, but larger negative numbers indicating that the item aligns better with an orbiting construct definition.

The results were as follows: SEE-E: $p_{s a}=.77, c_{s v}=.56$; SEE-I: $p_{s a}=.88, c_{s v}=.80$. According to the benchmarks for these indexes (i.e., focal constructs that share more moderate correlations [.35-.50] with orbiting scales) established by Colquitt and colleagues (2019), $p_{s a}$ and $c_{s v}$ results for SEE-E denote "moderate" content validity, while $p_{s a}$ and $c_{s v}$ results for SEE-I denote "strong" content validity. These findings suggest that, generally, participants were correctly able to categorize SEE items and that the SEE items were not consistently confused for an orbiting construct (i.e., miscategorizations were spread among orbiting constructs). This offers further evidence of the content validity of our SEE items. 
Table B1

\section{Appendix B}

Means, standard deviations, and correlations with confidence intervals for Study 2

\begin{tabular}{|c|c|c|c|c|c|c|c|c|}
\hline $\begin{array}{l}\text { Variable } \\
\text { 1. Age }\end{array}$ & $\begin{array}{c}M \\
35.5\end{array}$ & $\begin{array}{l}S D \\
10.5\end{array}$ & 1 & 2 & 3 & 4 & 5 & 6 \\
\hline 2. Hours & 39.9 & 6.90 & $\begin{array}{c}.00 \\
{[-.07, .07]}\end{array}$ & & & & & \\
\hline 3. Gender & 1.52 & 0.50 & $\begin{array}{c}.03 \\
{[-.04,-.10]}\end{array}$ & $\begin{array}{c}-.22^{* *} \\
{[-.28,-.14]}\end{array}$ & & & & \\
\hline 4. Abuse & 1.56 & 0.74 & $\begin{array}{c}-.10^{* *} \\
{[-.17,-.03]}\end{array}$ & $\begin{array}{c}.07 \\
{[-.00, .14]}\end{array}$ & $\begin{array}{c}-.14^{* *} \\
{[-.21,-.07]}\end{array}$ & .89 & & \\
\hline 5. SEE-I & 2.29 & 0.81 & $\begin{array}{c}-.01 \\
{[-.08, .06]}\end{array}$ & $\begin{array}{c}.16^{* *} \\
{[.09, .23]}\end{array}$ & $\begin{array}{c}-.02 \\
{[-.09, .05]}\end{array}$ & $\begin{array}{c}.16^{* *} \\
{[.09, .23]}\end{array}$ & .75 & \\
\hline 6. SEE-E & 1.89 & 0.78 & $\begin{array}{c}-.07 \\
{[-.14, .00]}\end{array}$ & $\begin{array}{c}.04 \\
{[-.03, .12]}\end{array}$ & $\begin{array}{c}.02 \\
{[-.05, .09]}\end{array}$ & $\begin{array}{c}.34^{* *} \\
{[.27, .40]}\end{array}$ & $\begin{array}{c}.49^{* *} \\
{[.43, .54]}\end{array}$ & .79 \\
\hline 7. OCB & 3.17 & 1.08 & $\begin{array}{c}.03 \\
{[-.5, .10]}\end{array}$ & $\begin{array}{c}.17^{* *} \\
{[.10, .24]}\end{array}$ & $\begin{array}{c}.01 \\
{[-.06, .08]}\end{array}$ & $\begin{array}{c}.30^{* *} \\
{[.23, .37]}\end{array}$ & $\begin{array}{c}.46^{* *} \\
{[.40, .51]}\end{array}$ & $\begin{array}{c}.36^{* *} \\
{[.29, .42]}\end{array}$ \\
\hline 8. Withdrawal & 1.86 & 0.79 & $\begin{array}{c}-.07 \\
{[-.14, .00]}\end{array}$ & $\begin{array}{c}.01 \\
{[-.07, .08]}\end{array}$ & $\begin{array}{c}-.14^{* *} \\
{[-.21,-.06]}\end{array}$ & $\begin{array}{c}.59^{* *} \\
{[.54, .63]}\end{array}$ & $\begin{array}{c}.10^{* *} \\
{[.02, .17]}\end{array}$ & $\begin{array}{c}.25^{* *} \\
{[.18, .31]}\end{array}$ \\
\hline 9. PD & 1.42 & 0.73 & $\begin{array}{c}-.16^{* *} \\
{[-.23,-.09]}\end{array}$ & $\begin{array}{c}.03 \\
{[-.04, .11]}\end{array}$ & $\begin{array}{c}-.18^{* *} \\
{[-.25,-.11]}\end{array}$ & $\begin{array}{c}.67^{* *} \\
{[.63, .71]}\end{array}$ & $\begin{array}{c}.07 \\
{[-.00, .14]}\end{array}$ & $\begin{array}{c}.25^{* *} \\
{[.18, .31]}\end{array}$ \\
\hline 10. WE & 4.41 & 1.27 & $\begin{array}{c}.12^{* *} \\
{[.05, .19]}\end{array}$ & $\begin{array}{c}.05 \\
{[-.02, .12]}\end{array}$ & $\begin{array}{c}.03 \\
{[-.04, .10]}\end{array}$ & $\begin{array}{c}-.04 \\
{[-.11, .03]}\end{array}$ & $\begin{array}{c}.17^{* *} \\
{[.10, .24]}\end{array}$ & $\begin{array}{c}-.03 \\
{[-.10, .04]}\end{array}$ \\
\hline 11. Job & 3.43 & 0.61 & $\begin{array}{c}0 \\
{[-.07, .08]}\end{array}$ & $\begin{array}{c}.02 \\
{[-.05, .09]}\end{array}$ & $\begin{array}{c}.06 \\
{[-.02, .13]}\end{array}$ & $\begin{array}{c}-.11^{* *} \\
{[-.18,-.04]}\end{array}$ & $\begin{array}{c}.04 \\
{[-.04, .11]}\end{array}$ & $\begin{array}{c}-.10^{* *} \\
{[-.17,-.02]}\end{array}$ \\
\hline 12. Microbreaks & 2.85 & 0.70 & $\begin{array}{c}-.19^{* *} \\
{[-.26,-.12]}\end{array}$ & $\begin{array}{c}.06 \\
{[-.01, .13]}\end{array}$ & $\begin{array}{c}-.02 \\
{[-.09, .05]}\end{array}$ & $\begin{array}{c}.30^{* *} \\
{[.23, .36]}\end{array}$ & $\begin{array}{c}.18^{* *} \\
{[.11, .25]}\end{array}$ & $\begin{array}{c}.25^{* *} \\
{[.18, .31]}\end{array}$ \\
\hline 13. PS & 3.28 & 1.19 & $\begin{array}{c}.06 \\
{[-.01, .14]}\end{array}$ & $\begin{array}{c}.13^{* *} \\
{[.05, .20]}\end{array}$ & $\begin{array}{c}.02 \\
{[-.05, .09]}\end{array}$ & $\begin{array}{c}.26^{* *} \\
{[.19, .32]}\end{array}$ & $\begin{array}{c}.50^{* *} \\
{[.44, .55]}\end{array}$ & $\begin{array}{c}.37^{* *} \\
{[.30, .43]}\end{array}$ \\
\hline
\end{tabular}


Table B1, cont.

\begin{tabular}{|c|c|c|c|c|c|c|c|}
\hline Variable & 7 & 8 & 9 & 10 & 11 & 12 & 13 \\
\hline 7. OCB & .96 & & & & & & \\
\hline 8. Withdrawal & $\begin{array}{c}.16^{* *} \\
{[.09, .23]}\end{array}$ & .81 & & & & & \\
\hline 9. PD & $\begin{array}{c}.23^{* *} \\
{[.16, .30]}\end{array}$ & $\begin{array}{c}.68^{* *} \\
{[.64, .72]}\end{array}$ & .86 & & & & \\
\hline 10. WE & $\begin{array}{c}.35^{* *} \\
{[.28, .41]}\end{array}$ & $\begin{array}{c}-.22^{* *} \\
{[-.29,-.15]}\end{array}$ & $\begin{array}{c}-.14^{* *} \\
{[-.22,-.07]}\end{array}$ & .96 & & & \\
\hline 11. JS & $\begin{array}{c}.16^{* *} \\
{[.09, .23]}\end{array}$ & $\begin{array}{c}-.14^{* *} \\
{[-.21,-.07]}\end{array}$ & $\begin{array}{c}-.16^{* *} \\
{[-.23,-.09]}\end{array}$ & $\begin{array}{c}.57^{* *} \\
{[.52, .62]}\end{array}$ & .91 & & \\
\hline 12. Microbreaks & $\begin{array}{c}.19^{* *} \\
{[.12, .26]}\end{array}$ & $\begin{array}{c}.45^{* *} \\
{[.39, .50]}\end{array}$ & $\begin{array}{c}.31^{* *} \\
{[.24, .37]}\end{array}$ & $\begin{array}{c}-.10^{* *} \\
{[-.17,-.03]}\end{array}$ & $\begin{array}{c}.01 \\
{[-.06, .09]}\end{array}$ & .79 & \\
\hline 13. PS & $\begin{array}{c}.92^{* *} \\
{[.91, .93]}\end{array}$ & $\begin{array}{c}.14^{* *} \\
{[.07, .21]}\end{array}$ & $\begin{array}{c}.19^{* *} \\
{[.12, .26]}\end{array}$ & $\begin{array}{c}.32^{* *} \\
{[.25, .38]}\end{array}$ & $\begin{array}{c}.16^{* *} \\
{[.09, .23]}\end{array}$ & $\begin{array}{c}.19^{* *} \\
{[.12, .26]}\end{array}$ & .85 \\
\hline
\end{tabular}

Note. $N=734$. Values in square brackets indicate the $95 \%$ confidence interval for each correlation. The confidence interval is a plausible range of population correlations that could have caused the sample correlation (Cumming, 2014). Omega values are in bold along the diagonal. Gender: $0=$ male, $1=$ female; SEE: Support Elicitation Experiences, I: Instrumental, E: Emotionally Laden; OCB: Organizational Citizenship Behavior; PD: Production Deviance; WE: Work Engagement; JS: Job Satisfaction; PS: Inferred Provision of Support.

$* p<.05, * * p<.01$. 